\title{
Chemically Oscillating Reactions during the Diagenetic Formation of Ediacaran Siliceous and Carbonate Botryoids
}

\author{
Dominic Papineau ${ }^{1,2,3,4, *}$, Jiayu Yin ${ }^{1}\left(\mathbb{D}\right.$, Kevin G. Devine ${ }^{5}$, Deng Liu ${ }^{4,6}$ and Zhenbing She ${ }^{4,6}$ \\ 1 Department of Earth Sciences, University College London, London WC1E 6BT, UK; anniekins39@gmail.com \\ 2 London Centre for Nanotechnology, University College London, London WC1H 0AH, UK \\ 3 Centre for Planetary Sciences, Birkbeck College, University College London, London WC1E 6BT, UK \\ 4 State Key Laboratory of Biogeology and Environmental Geology, School of Earth Sciences, China University \\ of Geosciences, Wuhan 430074, China; liudeng@cug.edu.cn (D.L.); zbsher@cug.edu.cn (Z.S.) \\ 5 Chemical and Pharmaceutical Sciences, School of Human Sciences, London Metropolitan University, \\ London N7 8DB, UK; K.Devine@londonmet.ac.uk \\ 6 School of Environmental Studies, China University of Geosciences, Wuhan 430074, China \\ * Correspondence: d.papineau@ucl.ac.uk
}

Citation: Papineau, D.; Yin, J.; Devine, K.G.; Liu, D.; She, Z.

Chemically Oscillating Reactions during the Diagenetic Formation of Ediacaran Siliceous and Carbonate Botryoids. Minerals 2021, 11, 1060. https://doi.org/10.3390/min11101060

Academic Editors: Avraam Zelilidis, Ioannis Iliopoulos and Georgia Pe-Piper

Received: 30 July 2021

Accepted: 23 September 2021

Published: 28 September 2021

Publisher's Note: MDPI stays neutral with regard to jurisdictional claims in published maps and institutional affiliations.

Copyright: (c) 2021 by the authors. Licensee MDPI, Basel, Switzerland. This article is an open access article distributed under the terms and conditions of the Creative Commons Attribution (CC BY) license (https:// creativecommons.org/licenses/by/ $4.0 /)$.

\begin{abstract}
Chemically oscillating reactions are abiotic reactions that produce characteristic, periodic patterns during the oxidation of carboxylic acids. They have been proposed to occur during the early diagenesis of sediments that contain organic matter and to partly explain the patterns of some enigmatic spheroids in malachite, phosphorite, jasper chert, and stromatolitic chert from the rock record. In this work, circularly concentric self-similar patterns are shown to form in new chemically oscillating reaction experiments with variable mixtures of carboxylic acids and colloidal silica. This is carried out to best simulate in vitro the diagenetic formation of botryoidal quartz and carbonate in two Ediacaran-age geological formations deposited after the Marinoan-Nantuo snowball Earth event in South China. Experiments performed with alkaline colloidal silica ( $\mathrm{pH}$ of 12) show that this compound directly participates in pattern formation, whereas those with humic acid particles did not. These experiments are particularly noteworthy since they show that pattern formation is not inhibited by strong $\mathrm{pH}$ gradients, since the classical Belousov-Zhabotinsky reaction occurs in solution with a $\mathrm{pH}$ around 2. Our documentation of hundreds of classical Belousov-Zhabotinsky experiments yields a number of self-similar patterns akin to those in concretionary structures after the Marinoan-Nantuo snowball Earth event. Morphological, compositional, and size dimensional comparisons are thus established between patterns from these experiments and in botryoidal quartz and carbonate from the Doushantuo and Denying formations. Selected specimens exhibit circularly concentric layers and disseminations of organic matter in quartz and carbonate, which also occurs in association with sub-micron-size pyrite and sub-millimetre iron oxides within these patterns. X-ray absorption near edge structure (XANES) analyses of organic matter extracted from dolomite concretions in slightly younger, early Cambrian Niutitang Formation reveal the presence of carboxylic and N-bearing molecular functional groups. Such mineral assemblages, patterns, and compositions collectively suggest that diagenetic redox reactions take place during the abiotic decay of biomass, and that they involve $\mathrm{Fe}$, sulphate, and organic matter, similarly to the pattern-forming experiments. It is concluded that chemically oscillating reactions are at least partly responsible for the formation of diagenetic siliceous spheroids and concretionary carbonate, which can relate to various other persistent problems in Earth and planetary sciences.
\end{abstract}

Keywords: chalcedony; agate; colloform; organic matter; Doushantuo formation; Raman spectroscopy

\section{Introduction}

The origin of curved and laminated patterns in botryoidal quartz is enigmatic. In botryoidal habit, quartz occurs as colourful banded cavity structures and they are common objects in mineral collections. The banding in botryoids is enigmatic, however, with varied 
colour gradients in geometrically perfect spherical to hemispherical forms of botryoidal quartz [1]. Crystallographic analyses have shown that quartz therein occurs as acicular crystals where the silica tetrahedra are organised in a screw-dislocation spatial arrangement [2]. An abiotic origin for these objects has been the main interpretation used in research on agate geodes and botryoidal quartz [3]. This is generally described in terms of spontaneous (abiotic), diffusive (e.g., Liesegang), and nucleation processes that lead to the self-assembly of these geometric spheroids. However, none of these inferred processes specifically predict the formation of the specific kinds of self-similar patterns encountered in geodes and botryoids. The concept of self-similarity is used here in the same sense as when used to describe fractal patterns, which are patterns of the same kind that repeat over many dimension scales. Recently, it has been proposed that chemically oscillating reactions might be responsible for the formation of these features in 'diagenetic spheroids' that are commonly circularly concentric, which include botryoids, geodes, concretions, nodules, granules, and rosettes [4-8]. The new model thus proposes an authigenic, diagenetic origin from nanoscopic precipitates of quartz (or opal), apatite, or carbonate in which these reactions oxidise organic matter (not necessarily from biomass) into carbonate, with the presence of strong oxidants and acids. The model proposes that abiotic oxidation of carboxylic functional groups from the organic matter ultimately drives the electromotive force and creates the diffusion of circularly concentric self-similar patterns. If the organic matter is biological in origin, the model then implies that botryoids can be biosignatures of past life, whereas if the carboxylic acids have a natural abiotic origin, then the model implies that botryoids are part of the abiotic carbon cycle. Both possibilities may exist and co-exist.

The first to recognise the formation of patterns during chemically oscillating reactions was Boris Belousov in the 1950s, after he photographed a film of solution with malonic acid, sulfuric acid, bromate and bromomalonic acid mixed with ferroin (phenanthroline ferrous sulfate) [9]. These characteristic Belousov-Zhabotinski (or "BZ") patterns form circularly-concentric sections that are erased where two meet and continue to propagate radially from their point of origin, which produces a characteristic pattern of interconnected circular arcs. The same kinds of patterns are associated with some fossils [10] or in geodes [1]. However, in other relevant cases in chert, amygdules in basalt, and botryoids, these reactions have not been considered as possible alternative explanations [11-13]. Indeed, there has been no comprehensive comparison of the morphological and chemical characteristics of the $\mathrm{BZ}$ reaction and geological features.

In this work, we first set out to test the hypothesis that chemically oscillating reaction can produce self-similar patterns with various carboxylic acids as reactants, to better simulate the natural decomposition of biomass. Then, new experiments also test whether the self-similar patterns can be produced in the presence of silicic acid in order to simulate siliceous media in nature. For comparison, we then document the detailed morphology, mineralogy, organic petrology, and composition of natural specimens of quartz-carbonate botryoids from the Doushantuo cap carbonate. The analytical approach consists in correlated polarising microscopy and micro-Raman imaging to obtain compositional and petrographic information from quartz botryoids and to establish detailed comparisons with the photo-documented BZ patterns. Four quartz botryoids were selected and come from the Doushantuo and Dengying formations. The three from the Doushantuo Formation (Fm) come from the cap carbonate unit, inferred to have deposited after the last snowball Earth event in Earth history. These localities and specimens were selected since the new model investigated fits particularly well in the context of biomass putrefaction and decomposition after a deglaciation. It is also possible that there is a connection between chemically oscillating reactions and quartz botryoids in rocks precipitated after the last snowball Earth event and thereby may be related to both the carbon cycle and climate evolution. 


\section{Geological Context of Studied Material}

Two botryoidal quartz specimens were collected from the basal Doushantuo Fm, also known as Member I. Both samples YG1801 ( $a$ and b) and YG1802 come from botryoidal crust lining the inside of two irregularly shaped metre-size cavities (Figure 1a-c) in the Jiulongwan locality in the Three Gorges area in Hubei Province (N: $30^{\circ} 48^{\prime} 38^{\prime \prime}$; E: $111^{\circ} 04^{\prime} 28^{\prime \prime}$ ), whereas sample DO1706 comes from so called sheeted-cracks (Figure 1d), a term used to emphasize the irregular contour of the cracks and their infilling with laminated quartz, in the Beidoushan locality in the Weng'an area, Guizhou Province (N: $27^{\circ} 01^{\prime} 10.7^{\prime \prime}$; E: $107^{\circ} 23^{\prime} 20.9^{\prime \prime}$ ). The samples from the Dengying Fm come from drill cores (ZK430 near Baizhu and ZK3208-9 near Kaiyang), and they display a decimetre thick layer of this type of botryoidal mineralisation composed of carbonate. One last sample (YG0902) of black shale with decimetre-size concretions from the Niutitang Formation, the lowermost Cambrian strata (N: $31^{\circ} 49^{\prime} 14.1^{\prime \prime}, \mathrm{E}: 111^{\circ} 10^{\prime} 24.9^{\prime \prime}$ ), was also chosen for an organic geochemical analysis. The Doushantuo and Dengying formations in South China are very well-preserved, generally metamorphosed only at the sub-greenschist facies, and they are widely exposed and relatively well-characterised.

The Doushantuo Formation in the area of the Three Gorges has an age constrained by U-Pb dating of zircons in tuff beds between 635 and $551 \mathrm{Ma}$ [14]. Other studies have provided $\mathrm{Pb}-\mathrm{Pb}$ isochron ages of $572 \pm 36 \mathrm{Ma}$ for Unit $4 \mathrm{~A}$ [15] and $599 \pm 4 \mathrm{Ma}$ for Unit $4 \mathrm{~B}$ [16]. Another U-Pb age of $609 \pm 5 \mathrm{Ma}$ has been reported from zircons in a tuff layer immediately above the upper phosphorite unit in Yichang (Member II), tentatively correlated with unit 4 in the Weng'an locality, $600 \mathrm{~km}$ to the southwest of Weng'an [17]. The Jiulongwan section near the three Gorges area in South China exposes all Members I to IV of the Doushantuo Fm along roadside outcrops. From stratigraphically lower to upper units are: Member I is a dolomitic cap carbonate unit with low $\delta^{13} \mathrm{C}_{\text {carb }}$ values (EN1—Excursion Negative 1; [18]) and cavities lined with botryoidal quartz. Member II is a black cherty and muddy carbonate unit with beds of chert nodules and granular phosphorite, which also contain numerous types of microbial microfossils [19] as well as low $\delta^{13} C_{\text {carb }}$ values (EN2-Excursion Negative 2; [18]). Member III is dominated by carbonate that occurs as interlayered limestone and dolostone, and near its top also occur negative $\delta^{13} \mathrm{C}_{\text {carb }}$ values (EN3-Excursion Negative 3; [18]). Then Member IV is an organic-rich black shale with metre-size concretions of cherty carbonate and is conformably overlain by the 551 to $542 \mathrm{Ma}$ Dengying formation [14]. The Dengying Fm also contains thick units of finely laminated carbonate with beds rich in decimetre size black chert nodules (Figure 1e). Finally, the lower Cambrian Niutitang Fm in the Three Gorges area outcrops as variably weathered black shales with sub-metre size carbonate concretions (Figure 1f). The regional geology is typically interpreted to represent paleo-environments that vary from lagoonal on the inner shelf to slope and basin on the outer shelf, respectively, approximately distributed from the northwest to the southeast along a general strike from northeast to southwest.

The Doushantuo cap carbonate contains significant ${ }^{13} \mathrm{C}$-depletions in its organic matter with $\delta^{13} C_{\text {org }}$ values down to $-40 \%$ [18] as well as in its carbonate minerals, with a large range of $\delta^{13} \mathrm{C}_{\text {carb }}$ between $+5 \%$ and $-41 \%$ [13]. While the former has been interpreted as a signature of ancient methane seeps, the latter was also recognised to have the most depleted $\delta^{13} \mathrm{C}_{\text {carb }}$ values at or near the geometric centres of dolomite clots and peloids, whereas dolomite botryoids usually had less ${ }^{13} \mathrm{C}$-depleted values of around $-6 \%$. These results have been largely reproduced, and, along with secular variations in S-isotopes and Fe-speciation contents, these geochemical trends appear to indicate a redox-stratified water-column in the inner shelf with a sulphidic water wedge in the outer shelf [20]. Other detailed C-isotope stratigraphic analyses have confirmed these trends and fluctuations in the C-cycle, and they have also shown that the inner shelf basin was host to various diagenetic cherty bands and nodules in carbonate, carbonate lenses and concretions, and cherty nodules [21]. The Dengying Fm is dominated by carbonate units, some with oolites, stromatolites, microbial laminae, botryoids, and various laminated dolostones with decimetre size fossiliferous black chert nodules and botryoids [22]. It conformably underlies the 
Lower Cambrian Niutitang Fm, in the Tongren area in Guizhou Province, and it preserves a negative C-isotope excursion in carbonate [23]. However, there currently lacks a systematic analysis of the mineralogy of the various types of concretionary structures from throughout the Doushantuo, Dengying, and Niutitang formations, and hence there is a knowledge gap about their significance in the post-snowball Earth world.
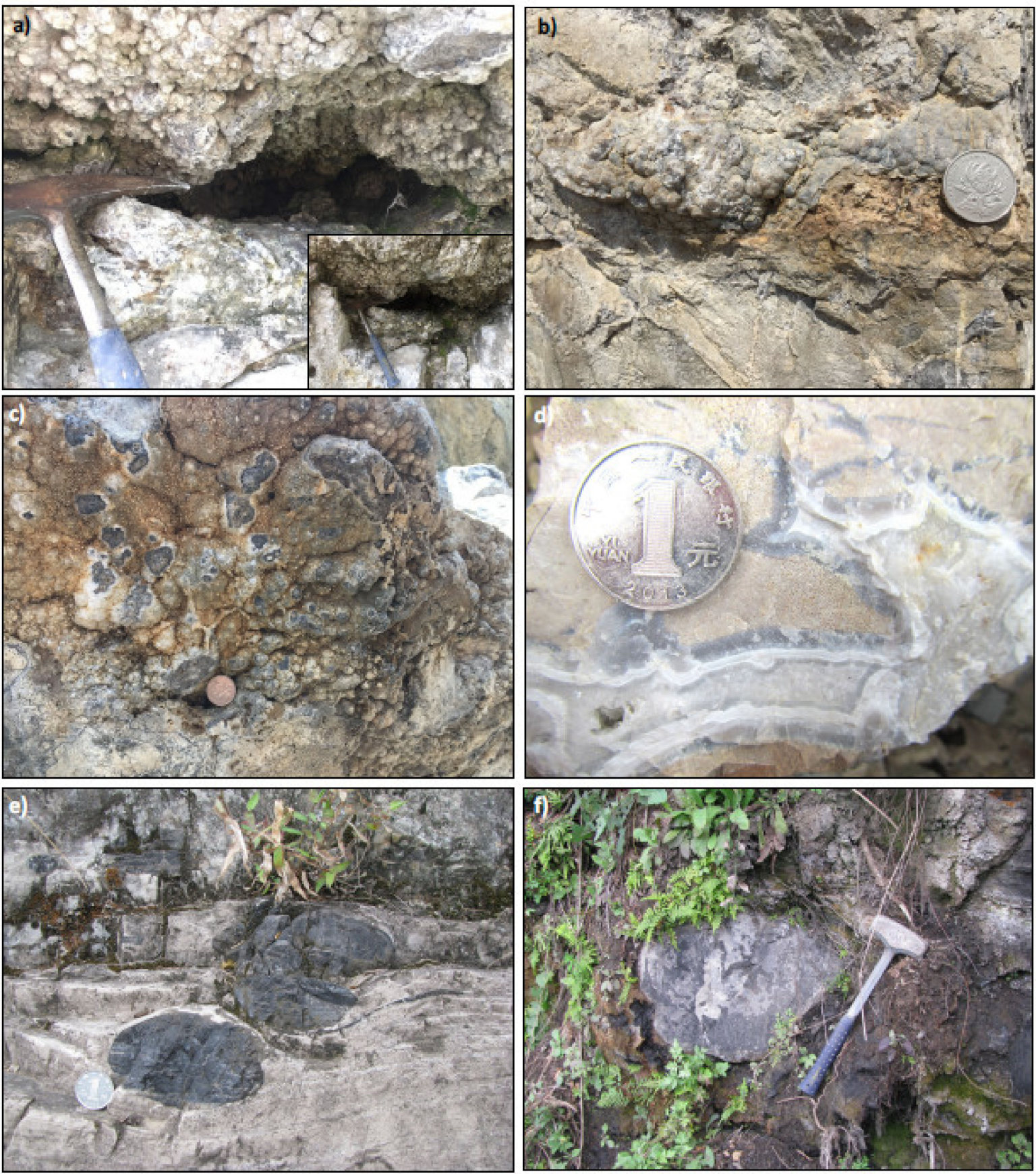

Figure 1. Outcrop images of quartz botryoids in Doushantuo cap carbonate, Member 1. (a) Cavity lined with a crust of botryoidal quartz (YG1801, Jiulongwan section). (b) Exposed cavity with quartz botryoids (YG1802; Jiulongwan section). (c) Another cavity with blackened carbonate caps under broken botryoids (Jiulongwan section). (d) So-called 'sheeted cracks' of quartz botryoids with fine curvi-linear laminations inside beige carbonate (DO1706; Beidoushan section). (e) Outcrop of black chert concretions in the Dengying dolomite (Three Gorges area) and (f) shows an outcrop of carbonate concretion in black shale from the Niutitang Fm (Three Gorges area). 


\section{Experimental and Analytical Methods}

Reactants for chemically oscillating reactions include the following: sodium bromate (Hopkin \& Williams), sodium bromate 99\% (Lancaster), sodium bromide (Hopkin \& Williams), malonic acid 99\% (Sigma-Aldrich), sulphuric acid (BDH), 1,10-phenanthroline monohydrate $99+\%$ (Alfa Aesar), and triton X-100 scintillation grade (BDH). Humic acids (Sigma Aldrich) and silicic acid reagent grade (Sigma-Aldrich) are also used in some experiments. One hundred millilitres of the following solutions are first prepared as stock reactant solutions for the experiments. Video recording is performed using a CCD camera held in a grip attached to a stand above the experiment. Lighting comes from a tabletop light emitting diode (LED) board with a millimetre-centimetre scale. Images presented are representative of overall reactions and are selected based on the types of patterns produced. For this study, new data are collected from both chemically oscillating reactions and the botryoidal quartz-carbonate specimens. This section first describes the different types of experiments performed with chemically oscillating reactions, and then describes optical microscopy and micro-Raman imaging of the selected specimens.

\subsection{Chemically Oscillating Reactions and the Classical BZ Reaction}

To perform these reactions, the classical BZ reaction with the following amounts of stock reactant solutions are used:

1. $6 \mathrm{~mL}$ of Solution $\mathrm{A}: 15 \mathrm{~g} \mathrm{NaBrO}_{3}[1 \mathrm{M}]+\mathrm{H}_{2} \mathrm{SO}_{4}[0.33 \mathrm{M}]$ premixed solution in $\mathrm{H}_{2} \mathrm{O}$

2. $1 \mathrm{~mL}$ of Solution B: Malonic acid $\left(\mathrm{C}_{3} \mathrm{H}_{4} \mathrm{O}_{4}\right)[1 \mathrm{M}]$ diluted in $\mathrm{H}_{2} \mathrm{O}$

3. $0.5 \mathrm{~mL}$ of Solution $\mathrm{C}: \mathrm{NaBr}[1 \mathrm{M}]$ diluted in water

4. $1 \mathrm{~mL}$ of phenanthroline ferrous sulfate solution: Ferroin $\left(\mathrm{C}_{36} \mathrm{H}_{24} \mathrm{FeN}_{6}{ }^{2+}\right)[25 \mathrm{mM}]-1 \mathrm{~mL}$

5. 1 drop of a non-ionic surfactant: Triton X-100 $\left(\left(\mathrm{C}_{14} \mathrm{H}_{22} \mathrm{O}\left(\mathrm{C}_{2} \mathrm{H}_{4} \mathrm{O}\right)_{n}\right)\right.$

Later in the text, the use of $\mathrm{BZ}$ solution refers to the mixed solution with the above reactants. All experiments are performed in clean Petri dishes of borosilicate glass using clean, disposable $3 \mathrm{ml}$ plastic pipettes. First, Solutions A and B are added and gently mixed, and immediately, a distinct public-pool-like bromine gas smell is generated. Then solution $C$ is added and again the Petri dish is gently shaken to allow even mixing of the solutions until the yellow-coloured solution becomes completely colourless. Finally, after this occurs, $1 \mathrm{ml}$ of ferroin and one drop of Triton X-100 are added and the Petri dish gently shaken until uniformly mixed. The ferroin contributes to the development of contrasting visible colours of orange-red and purple-blue colours, that result from its oscillation between two main oxidation states $\left(\mathrm{Fe}^{2+}\right.$ and $\left.\mathrm{Fe}^{3+}\right)$. The last stirring mixing was performed on the tabletop LED board to optimize the visual contrast of colours and obtain transmitted light illumination. Experiments are repeated at least in triplicates to document the formation of self-similar patterns.

\subsection{Chemically Oscillating Reaction Experiments with Other Carboxylic Acids}

The BZ reaction is tested with other carboxylic acids including succinic acid and alphaketoglutaric acid, involved in the Tricarboxylic Acid Cycle (TCA). These alternative organic molecules, along with humic acid, were selected due to their common occurrence in biology and in decayed biomass, although we acknowledge that there are many other compounds that should be tested in the future. The selected carboxylic acids are commercially supplied in powdered form (both obtained from Sigma-Aldrich) and also dissolved in deionised water also with a concentration of $1 \mathrm{M}$. Each of these two carboxylic acids is tested for the production of self-similar patterns used in a chemically oscillating reaction either as a replacement for malonic acid or in combination with malonic acid. Lastly, the three acids are used together to see if the chemically oscillating reaction would also produce self-similar patterns. The results of these are documented as images and then used to determine the design of later experiments. 


\subsection{Chemically Oscillating Reaction Experiments with Humic Acid}

To test the interaction of the chemical oscillations or waves with the presence of particulate organic matter, thereby more accurately simulating a natural geological setting, humic acid is used. Powdered humic acid is not dissolved, but is obtained in the form of humic acid sodium salt, which acts as an "aggregate" in the $\mathrm{pH}$ neutral reaction solution. This is applied to the reaction in two ways to verify that the number and density of particles in the solution can affect the chemical oscillations or waves. In the first instance, only a few particles of humic acid are deposited in a central area of the Petri dish with a freshly mixed BZ solution and poured into a Petri dish. The second instance starts with spreading humic acid particles near the edge of the Petri dish by depositing humic acid salt particles along the outer edge of the dish. This is carried out to simulate the walls of a rock cavity that could be filled with fluids similarly to those in the BZ solution, for instance during organic diagenesis.

\subsection{Chemically Oscillating Reactions in Colloidal Silica}

This series of experiments is meant to visualise whether self-similar patterns are still produced in the presence of silicic acid, an expected precursor to opal and quartz botryoids. Colloidal silica commonly precipitates in the reagent grade sodium silicate solution of high $\mathrm{pH} 12$. The selected part is the gel-like precipitate of silica settled at the bottom of the container, collected with a spatula. It is then rinsed six times with distilled water and mixed vigorously. When this is completed, the solution $\mathrm{pH}$ is expected to decrease progressively with each rinse step. The residue is then used in four instances for chemically oscillating reactions. In the first instance, it is directly added to the solution using a disposable pipette for smaller particles and a clean spatula for a larger mass of silica colloids. In the second instance, the BZ reaction is performed in a Petri dish before masses of wet colloidal silica are added at a few locations in the Petri dish. In the third instance, the silicic acid is added to uniformly cover the bottom of the Petri dish and dried overnight in air before the addition of the BZ solution. Lastly in some experiments, several grams of silica gel masses are added in the BZ reaction. The reaction is repeated with varying amounts of silica on the dish (varying thicknesses of dried colloidal silica) and also with different combinations of carboxylic acids within this colloidal silica medium. Generally, only the combination of reactants from the classical BZ reaction and which produce self-similar patterns are used in these experiments with colloidal silica. One last chemically oscillating reaction is carried out with all the previous experiments combined on a dried bed of colloidal silica: malonic, succinic and alpha-ketoglutaric acids all $1 \mathrm{M}$ and in equal amounts $(1 \mathrm{ml})$, a quarter of a gram of humic acid sprinkled onto the dish.

\subsection{Polarising Microscopy of Petrographic Thin Sections of Quartz Botryoids}

Thin sections of the rock samples are observed with an Olympus BX51 polarising optical microscope and a UC-50 CCD camera (Tokyo, Japan). Each sample with botryoids is documented in plane polarised (transmitted) light as well as in cross-polars and reflected light in the petrographic context of thin sections. Systematic observations lead to the identification of several target areas in each thin section and documented with magnifications of $50 \times, 100 \times, 200 \times, 500 \times$, and $1000 \times$. Cross polarized light microscopy is also used to identify minerals and relationships between minerals, grain boundaries, and occasional cross-cutting veins. Reflected light is also used to highlight certain features or to verify the topography of the sample surface before micro-Raman analysis. Two to three micro-Raman image scans are then collected on selected targets for each of the four studied thin sections.

\subsection{Micro-Raman Spectroscopic Imaging}

Micro-Raman analyses are performed with an $\alpha 300$ WITec Confocal Raman imaging system (Ulm, Germany) according to standard methods used on various other samples $[4,5,7]$. The laser wavelength is $532 \mathrm{~nm}$ and the power was set to $7-8 \mathrm{~mW}$ and the objective used is a long working distance $100 \times$ magnification. An integration time of 
$0.6 \mathrm{~s}$ to $0.8 \mathrm{~s}$ per pixel was used on the fours selected targets, and these conditions yield a spatial resolution of 2 pixels per micron. Images are produced using the WITec software (Four plus, WITec, Ulm, Germany) and filters are created for each phase detected: $344 \mathrm{~cm}^{-1}$ (width $10 \mathrm{~cm}^{-1}$ ) for pyrite in yellow, $1608 \mathrm{~cm}^{-1}$ (width $70 \mathrm{~cm}^{-1}$ ) for organic matter in red or pink, and $465 \mathrm{~cm}^{-1}$ (width $30 \mathrm{~cm}^{-1}$ ) for quartz in blue. Average spectra shown were extracted from masks with similar pixel spectra and intensity, which were first processed for cosmic ray reduction and then background subtracted, with a polynomial fit of order 5 or 6 over all the peak-less spectral regions.

\subsection{Scanning Transmission X-ray Microspectroscopy (STXM) of Acid-Insoluble Organic Matter}

To determine molecular functional group content in organic matter from this timeperiod in South China, the finely laminated, concretionary black shale YG0902 from the Niutitang Fm. is deemed an ordinary specimen with plentiful organic matter to extract and determine its content of molecular functional groups. Two sub-specimens are studied from this sample: YG0902a is the shale matrix and YG0902b is the carbonate concretion. Extraction from bulk powder was performed using $\mathrm{CsF}$ and $\mathrm{HF}$ according to the method described in Alexander et al. [24]. Briefly, a CsF-HF solution treatment is used to dissolve bulk powders with this CsF solution set to a density of $1.8 \mathrm{~g} / \mathrm{cm}^{3}$. Dioxane is then used to generate a separate solution of lower density, which floats on top of the CsF. The organic matter was observed to have a density less than $1.8 \mathrm{~g} / \mathrm{cm}^{3}$, but more than the low density of dioxane, which leads to the accumulation of organic matter at the interface. A muffled glass pipette is then used to aspire the organic matter, which is transferred to a muffled glass vial. A few rinses with new dioxane help dilute residual CsF and thus prevent salt crystal formation during subsequent drying in a laminar air flow hood. Aliquots of the organic isolate are then microtomed to $100 \mathrm{~nm}$ with a diamond knife and deposited on a silicon monoxide-coated $\mathrm{Cu}$ grid with thin bars for C-XANES analyses.

Samples are analysed on the polymer STXM beamline 5.3.2.2 at the Advanced Light Source (ALS), Lawrence Berkeley National Laboratory [25]. Analytical conditions are identical (same session) to those described in Papineau et al. $[4,5,26]$. X-ray spectroscopy was performed with images using a highest spectral resolution of $0.1 \mathrm{eV}$ per step for the regions of the edges of $\mathrm{C}, \mathrm{N}$, and $\mathrm{O}$, while the full spectra are collected with line scans between 280 and $575 \mathrm{eV}$, which covers the range of these three elements. For carbon, the spectral resolution is $0.1 \mathrm{eV}$ in the $282-292 \mathrm{eV}$ range, which is specifically the location of near-edge spectral features for electronic transitions from core $(1 \mathrm{~s})$ shell states to antibonding $\sigma^{*}$ - and $\pi^{*}$-orbitals. XANES spectra are presented as the ratio of transmission spectra from the region of interest, $\mathrm{I}$, relative to background transmission spectra, $\mathrm{I}_{\mathrm{O}}$, calculated as $\mathrm{A}=-\ln \left(\mathrm{I} / \mathrm{I}_{\mathrm{O}}\right)$.

\section{Observations of Circularly Concentric Fractal Patterns}

\subsection{Results from New Chemically Oscillating Experiments}

Abiotic, spontaneous and out-of-equilibrium chemically oscillating reactions performed in experiments have successfully produced patterns with the various recognisable BZ features as classified in Table 1 and shown in Figure 2, and describable as self-similar fractal patterns. The BZ patterns are seen as contrasting colours created by the coordination of iron with three phenanthroline complex in the presence of sulphate (in ferroin) and sulphate. From the natural orange-red and greenish colours of ferric and ferrous minerals, respectively, the similar contrasting colours in a chemically oscillating reactions are expected to arise from reduced reaction products, but over time, these make periodic, radially-expanding, and self-propagating circularly concentric waves. Over time they produce $\mathrm{CO}_{2}$ bubbles that stay attached to the borosilicate glass through surface tension. In summary, these reactions are spontaneous, abiotic, and they produce characteristic self-similar patterns. 
Table 1. Characteristics of BZ patterns classified by the most common types of simple features.

\begin{tabular}{|c|c|c|c|c|c|c|c|}
\hline Features & $\begin{array}{c}\text { Botryoidal } \\
\text { Quartz in } \\
\text { Doushantuo } \\
\text { Cap } \\
\text { Carbonate }\end{array}$ & $\begin{array}{l}\text { Classical } \\
\text { BZ Reaction }\end{array}$ & $\begin{array}{c}\text { BZ with } \\
\text { Malonic and } \\
\text { Succinic }\end{array}$ & $\begin{array}{c}\text { BZ with } \\
\text { Malonic and } \\
\text { Alpha- } \\
\text { Ketoglutaric }\end{array}$ & $\begin{array}{l}\text { BZ with } \\
\text { Humic Acid }\end{array}$ & $\begin{array}{c}\text { BZ with } \\
\text { Humic Acid } \\
\text { and all Three } \\
\text { Carboxylic } \\
\text { Acids }\end{array}$ & $\begin{array}{l}\text { BZ with } \\
\text { Colloidal } \\
\text { Sillica }\end{array}$ \\
\hline $\begin{array}{l}\text { Parallel banding/destructively } \\
\text { interfered laminations }\end{array}$ & Yes & Yes & Yes & Yes & Yes & Yes & Yes \\
\hline Circularly concentric oxidation spot & Yes & Yes & Yes & Yes & Yes & Yes & Yes \\
\hline Oxidation spiral & $?$ & Yes & Yes & Yes & Yes & Yes & Yes \\
\hline Cavity structure & Yes & Yes & Yes & Yes & Yes & Yes & Yes \\
\hline Irregular/subrounded lines & Yes & Yes & Yes & Yes & Yes & Yes & Yes \\
\hline Open book structure & Yes & Yes & Yes & Yes & Yes & Yes & Yes \\
\hline Colour gradient in chemical waves & Yes & Yes & Yes & Yes & Yes & Yes & Yes \\
\hline fingerprint/ripple pattern & No & Yes & Yes & Yes & No & No & No \\
\hline
\end{tabular}

Notes: 'Yes' means it is produced, gray 'Yes' means it is observed in every experiment. Blue background is when the feature is observed mostly towards the end of the experiment (after more than $15 \mathrm{~min}$ ), orange background is when the feature is observed near the start of the reaction. 'No' means 'not observed'.
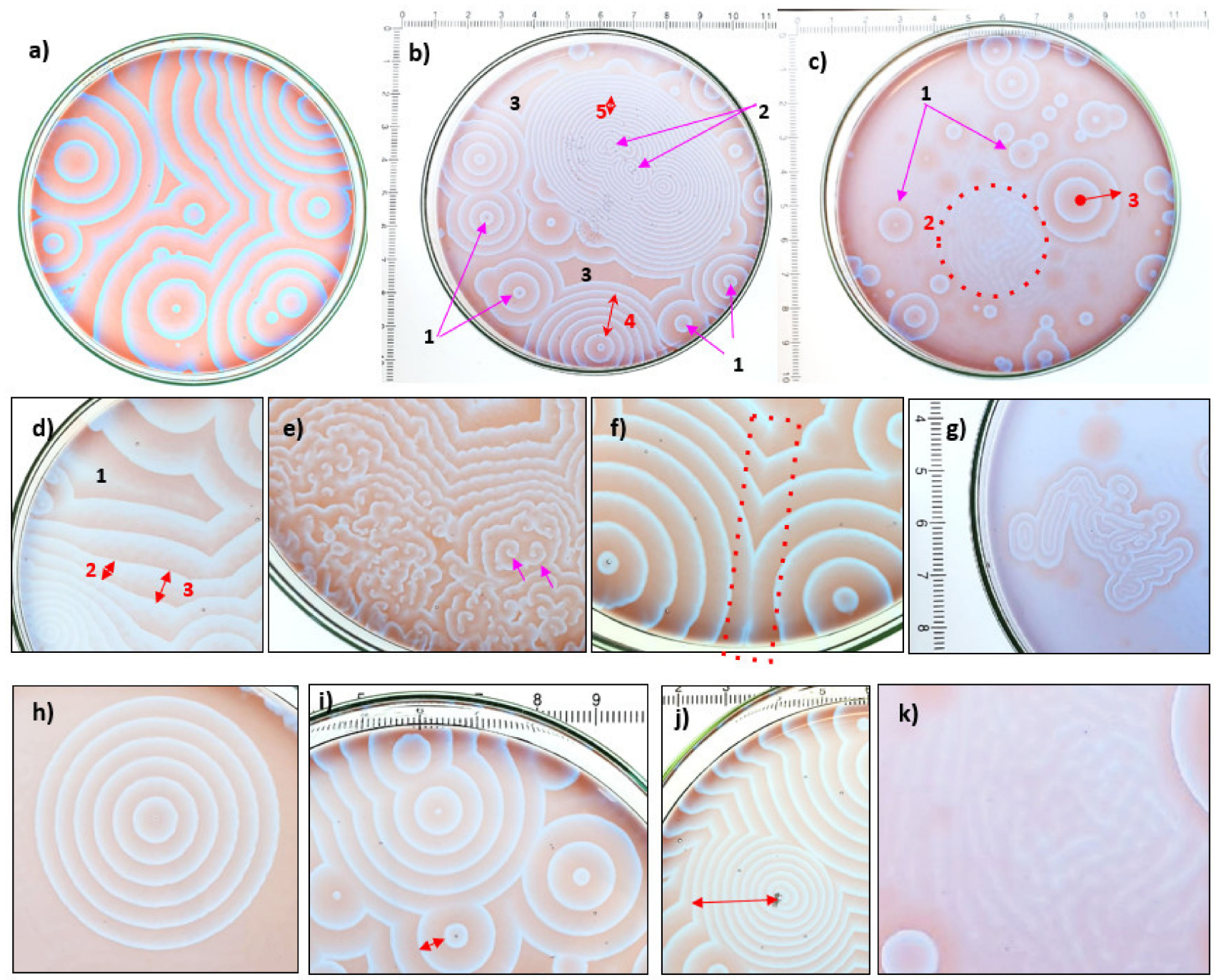

k)

Figure 2. The most common types of self-similar patterns produced for this work by the classical B-Z reaction in Petri dishes $10 \mathrm{~cm}$ in diameter. 
(a) Typical cavity structure near the centre that form as a result of the destructive interference between converging chemical oscillations (circular waves) from surrounding oxidation spots. (b) B-Z reaction that features oxidation spots (1), late-stage spirals in the centre of early oxidation spots (2), cavity structures (3), and two different wavelengths of chemical oscillations in medium frequency oscillations (4) and high frequency oscillations (5) (red arrows indicate the lengths of five redox cycles in each case). (c) Another B-Z reaction that shows oxidation spot (1) surrounding a "fingerprint" like pattern (2). Here each chemical oscillation nicely displays a gradient of colour (3) from orange-blue shades to blue then sharply orange again in the next wave. (d) Portion of a B-Z reaction that shows an open cavity (1) where long colour gradients are seen in chemical waves that define the cavity structure. Other features here are irregular waves where the distance between oscillation waves is not equal throughout a single wave ( 2 and 3 ), and sub rounded waves are not circular arcs. (e) A zone of spirals (purple arrows) in a B-Z reaction where the distinct wave patterns start to break up, which creates irregular ripple- or clot-like structures. (f) Red dotted rectangle highlights destructively interfered intersections of chemical waves, which resembles an "open book" structure. Note that the intersections of this open-book feature joined up form a straight line with the destructively interfered chemical wave either leaving a blurred trace and sometimes perfectly erased. (g) Closeup of a B-Z reaction that forms filamentous structures surrounded by concentric equidistant elongated waves. Similar to oxidation spots and spirals, these are elongated but also observed to be oxidation spots of chemical waves during the reaction. Magnified views of (h) perfect circularly concentric oxidation spot, (i) long period chemical waves with low frequency oscillations (red arrow shows a period of about $5 \mathrm{~mm}$ ), (j) short period chemical waves with high oscillation frequency (red arrow shows about 10 waves over $20 \mathrm{~mm}$, so the period here is about $2 \mathrm{~mm}$ ), and lastly (k) "fingerprint" like pattern.

In a typical reaction under standard conditions, the Petri dish in the early phase is mostly dominated by oxidation spots (Figure $2 \mathrm{a}-\mathrm{c}$ ), which accumulate as equidistant concentric rings, each with a gradient of the blue-violet-grey colour (Figure 2d). After many chemical waves have been generated, and in late reaction stage, they tend to pack more closely and eventually the central spot transitions into spirals (Figure 2e), usually towards the end of the reaction, some 15-20 min after a stir. Eventually, a process of destructive interference leaves interacting chemical waves perfectly erased, or leaves a blurred ghostly trace, thereby forming an open book structure (Figure 2f). Occasionally, filamentous structures surrounded by concentric equidistant elongated waves form linear patterns (Figure 2g). Lastly, experiments variably produce perfect circularly concentric oxidation spots (Figure $2 \mathrm{~h}$ ), chemical waves with long period and thus low frequency oscillations (Figure 2i), or with short period and high oscillation frequency (Figure 2j), as well as fingerprint-like or ripple patterns (Figure 2k).

More nature-like conditions are then used to visualise the self-similar BZ patterns with different additives as agglomerates of solid particles of humic acids and silicic acid precipitates. While all such experiments, reported in Figures 3 and 4, produce BZ patterns, all these experiments eventually produce $\mathrm{CO}_{2}$ as seen with the accumulation and release of bubbles through the progress of each experiment. First, the addition of particles of humic acid to the experiment is rapidly redistributed near the edge of the Petri dish by the surface tension of the aqueous solution (Figure 3a). Under such conditions, the formation of all self-similar BZ pattern types is unimpeded and unaffected by the presence humic acid, which is not seen to influence the location of oxidation spot as none are co-located (Figure 3a-h). Hence the sequence of images of a single experiment over $25 \mathrm{~min}$ with three types of carboxylic acids and humic acid masses (Figure $3 \mathrm{c}-\mathrm{h}$ ) shows that humic acid does not directly participate in the chemical oscillations, but that it may slightly disrupt the laminations. However, humic acid can serve as geometric centres for the oxidation spot, however this is not always seen. Some lone oxidation spot begins to develop into a spiral form after only about four min (Figure 3c). An irregular geometry of some oxidation spots is noted and these appear to be amplified by the presence of humic acids (Figure 3c). As the spiral continue to develop (Figure 3d-e), other nearby spirals sprawl nearby (Figure 3f-g) and while most humic acid particles move towards the edge of the dish due to surface tension, only their locations shift, not the self-similar BZ patterns in the aqueous solution. After cavity closure (Figure 3g) and towards the end of the experiment, the geometry of the waves becomes less sharp, and while the cavity continues to collapse, the cavity pattern remains and the spirals lose their form (Figure $3 \mathrm{~h}$ ). Out of the three tested carboxylic 
acids (malonic, succinic and $\alpha$-ketoglutaric acids), only malonic acid by itself produced self-similar BZ patterns. Tests with succinic acid and $\alpha$-ketoglutaric acid substituted from the malonic acid resulted in a fast and unique colour change of the ferroin from the initial red-orange colour to the blue-violet-grey reduced state (not shown). However, new observations show that mixtures or different carboxylic acids with malonic acid do not hinder the production of self-similar fractal patterns and produce $\mathrm{CO}_{2}$ bubbles after about $12 \mathrm{~min}$ (Figure $3 \mathrm{c}-\mathrm{h}$ ). The types of patterns produced by reactions using a mixture of malonic acid plus other carboxylic acids produced patterns indistinguishable from those produced by a malonic acid only reaction solution. These observations collectively suggest that these compounds are also decarboxylated when they are mixed into the reaction.
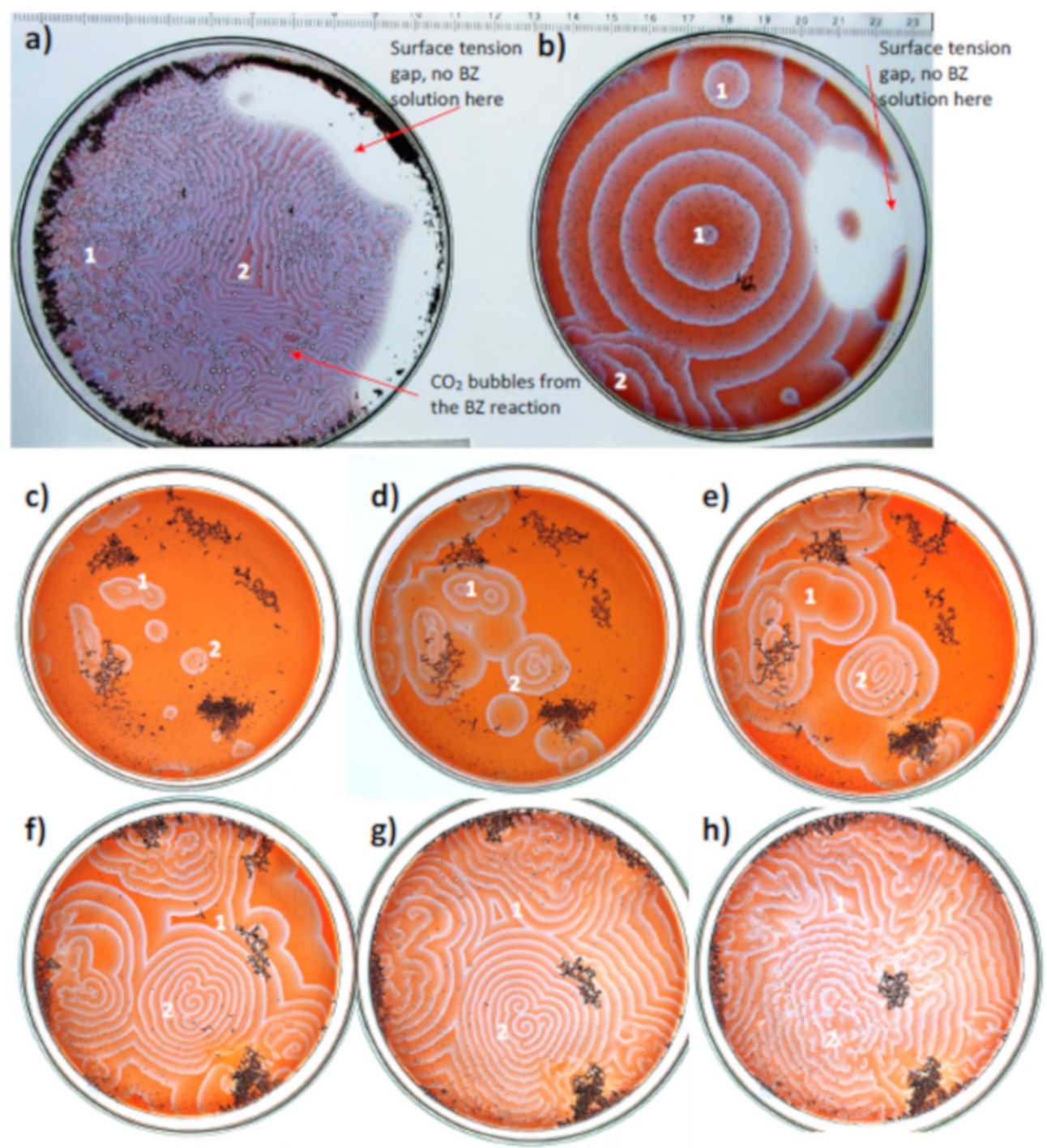

Figure 3. (a) and (b) Standard BZ reaction solution with the addition of humic acid particles (black) in the Petri dish prepared simultaneously. One full spatula of humic acid was initially placed on the dish with the BZ solution poured after. The motion and surface tension of the solution displaced the particles to the edge. This photo was taken after more than $15 \mathrm{~min}$ into the reaction and featuring zones of chaotic spiral patterns (1), a large number of CO2 bubbles throughout (small white disks with thin black rims), and a closed cavity (2). b) Same experiment with a small amount of particles placed in the centre of the dish with the mixed BZ solution being poured after the addition of humic acid. The experiment was mainly one central oxidation spots with lower frequency waves than Petri dish "a)" along with smaller carbon dioxide gas bubbles despite the almost simultaneous start time of the reactions. 
The bottom left of the dish also featured irregular waves (2) which display destructive interference with waves from the central spot. (c-h) show the progression of a reaction at four-minutes intervals over 25 mins in that respective order. In the petri dish contains BZ solution involving $1 \mathrm{ml}$ of all the three carboxylic acids at $1 \mathrm{M}$ concentration with $2 \mathrm{ml}$ of dilute sodium silicate solution added in. In addition, there was a quarter spatula of humic acid salt sprinkled on top. (c) The early second wave formation of oxidation spots ( 1 and 2 ) irrespective of the presence of humic acid floating on the surface of the solution. Note the irregular geometry of the oxidation spots. (d) The double oxidation spots (1) has grown to the 3rd wave and the first wave has met destructive interference with the other oxidation spot. A lone oxidation spot (2) starts to develop into a spiral form. (e) The double oxidation spots (1) cease to produce new waves from those spots whereas the spiral (2) continues to develop. (f) The middle spiral (2) develops additional spirals nearby while most humic acid particles move towards the edge of the dish due to surface tension. (g) The open cavity is closed (1) whereas the spirals (2) form new waves. (h) Towards the end of the BZ reaction, the geometry of the waves becomes less sharp, where the cavity (1) continues to collapse and the spirals (2) loose their form.

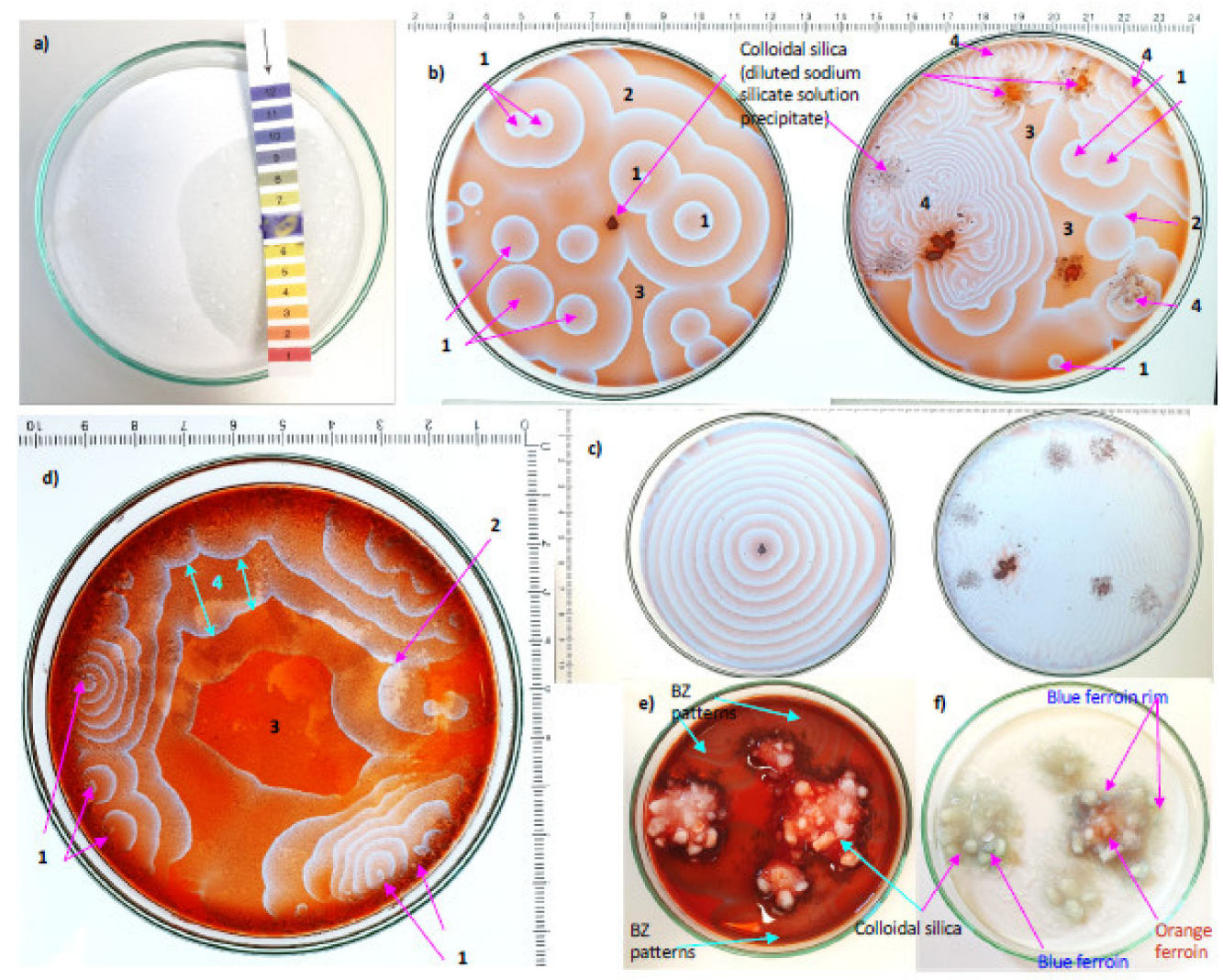

Figure 4. Chemically oscillating reactions in a Petri dish enriched with colloidal silica. Area of uniformly distributed colloidal silica rehydrated with DI water has an alkaline $\mathrm{pH}$ of more than 12 , as seen on the indicator strip. (b) Classical B-Z reaction with the addition of colloidal silica particles near the centre of the Petri dish. One spatula full of silica scattered throughout the right dish. Both dishes feature point centre oxidation spots (1) and open book features (2) from destructive interference of circular waves along with cavities (3). (a) On the dish to the right with more silica, spirals form (4) with high frequency oscillations, while the waves become irregular. Note the occurrence of spirals in proximity to the silica. (c) Duplicate reactions from "b)" after 40 mins. Note that the colour of ferroin is mostly blue after so long and the strong colour gradients. The left dish is dominated by a single oxidation spot with low frequency oscillations that originate from the central silica particle. The right dish shows the solution is mostly blue with high frequency oscillations self-similar patterns. 
(d) BZ reaction from standard BZ solution poured onto a dish prepared with dried sodium silicate solution as seen in a). Most sites of wave generation are all spirals (1) with waves from different sites destructively interfering forming open an book feature (2). A cavity (3) resides in the middle of the dish as the spirals (1) are located nearer to the edge of the dish. Waves are mostly irregular with variable frequencies (4). The dark rim near the edge is a thicker layer of colloidal silica and slightly obscures some of the BZ patterns. (e) and (f) Standard BZ reaction solution after the addition of large masses of colloidal silica in the petri dish where (e) irregular equidistant rims of blue ferroin form around the masses of silica 5 mins after the start, and (f) the same dish, left overnight, approximately $18 \mathrm{~h}$ after with preserved different redox states of ferroin.

Sodium silicate solution has a very high $\mathrm{pH}$ around 12 (Figure $4 \mathrm{a}$ ), which results in a thermodynamic disequilibrium when colloidal silica contacts the acidic BZ solution. This effect is shown in Figure 4 b, where colloidal silica added as scoopfuls in classical BZ experiments is seen to cut laminations formed by chemical waves. After forty minutes, this experiment turned mostly light blue with highly diffused BZ patterns and long colour gradients in each chemical wave. In one BZ experiment with colloidal silica (Figure 4a, left), the clump of colloidal silica becomes the main geometric centre of what develops into a single, decimetre size oxidation spot (Figure 4c). For some of the colloidal silica experiments, the entire dish was prepared with a layer of dried colloidal silica providing a uniformly high pH environment (Figure $4 \mathrm{a}$ ) once rehydrated. The presence of BZ patterns under such conditions (Figure $4 \mathrm{~d}$ ) confirms that these widely different $\mathrm{pH}$ do not impede the formation of BZ patterns. Another notable result from these experiments is the preservation of different colour gradients, which represent different oxidation states of ferroin, in the colloidal silica (Figure 4e-f). In one of those Petri dishes, the BZ patterns are formed in the solution surrounding the large agglomerates of colloidal silica, and a thick rim of blue and red ferroin is produced (Figure 4e). After several hours these different colours are still preserved in colloidal silica.

\subsection{Results from Polarising Microscopy of Quartz Botryoids from the Post-Snowball Carbonate}

Polished petrographic thin section of the Doushantuo and Dengying formations show millimetre to centimetre size botryoidal features (Figure 5). Jiulongwan sample YG1801 has botryoidal quartz in specific regions and a matrix of carbonate orange to brown in colour (Figure 5a) and gray (Figure 5b). In another specimen from Jiulongwan, YG1802, there are banded patterns in quartz botryoids (Figure $5 \mathrm{c}$ ). Sheeted crack in cap carbonate from Beidoushan (DO1701) have botryoids lined with organic matter (Figure 5d) and the dolostone samples from the Dengying Fm. has the same type of self-similar patterns as those in sheeted cracks (Figure 5e,f). Microscopy images in plane polarised light show the transparency of quartz is affected by the presence of variable concentrations of brown, finely disseminated organic matter and it is clear from these images that the circularly concentric laminations have the same kind of self-similar patterns (Figure 6) as those produced by the classical BZ reaction and the variants tested in this work. In Doushantuo and Dengying specimens, the most common types of pattern features are the circular concentricity, cavity structures, open book structures, and colour gradients (Figure 6a-d and Table 1). It is important to note that all the circularly concentric patterns preserved in quartz and carbonate are lined with some finely disseminated organic matter (OM), which commonly forms colour gradients due to their variable concentration, distributed into geometrically perfect self-similar patterns. 

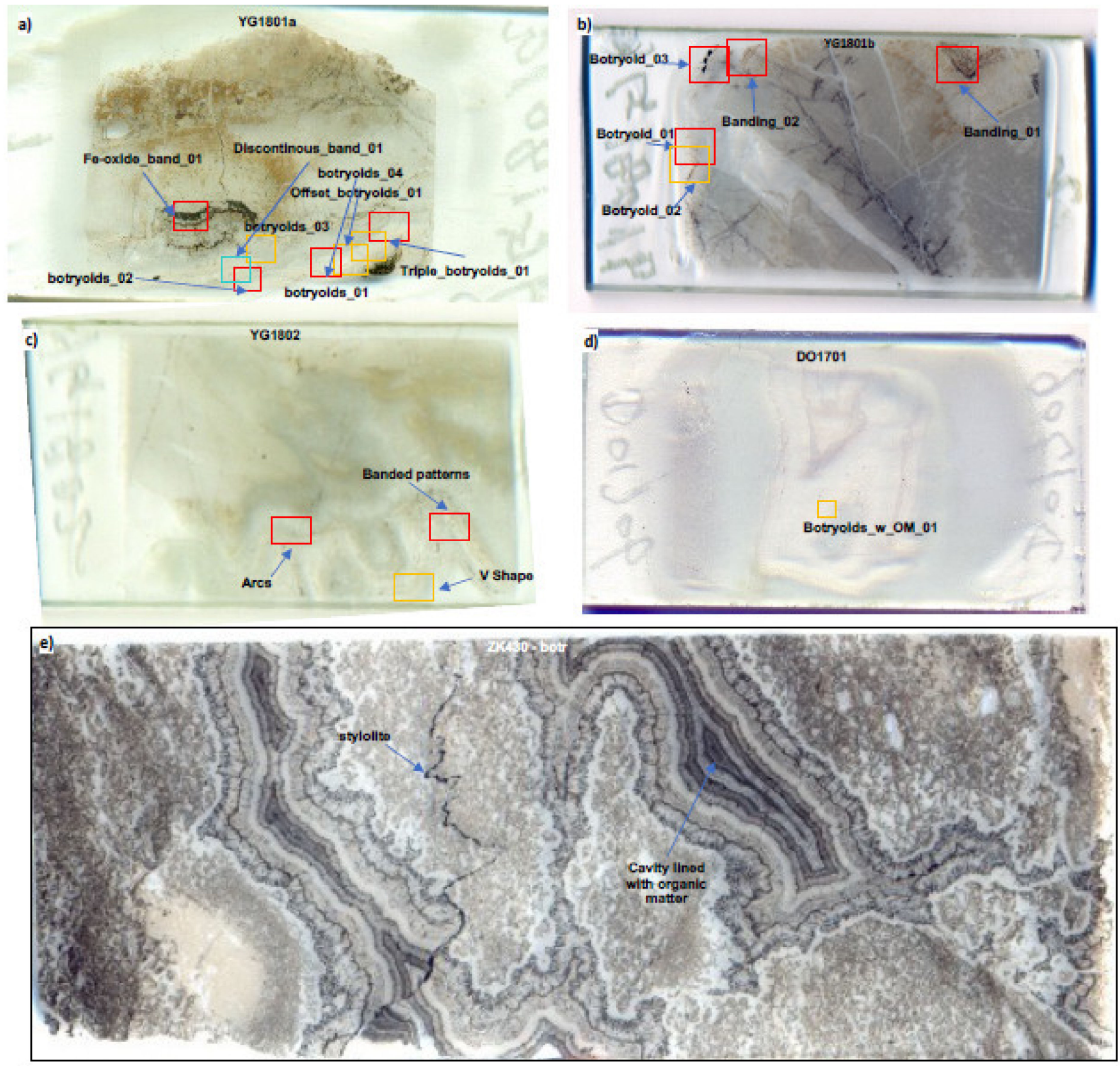

Figure 5. Transmitted light images of the thin sections of the studied rock samples. (a) and (b) Thin sections of two sub-samples of the heterogeneous Doushantuo quartz botryoids (YG1801). (c) Quartz botryoids from another cavity from the Doushantuo member I (YG1802). (d) botryoidal quartz from 'sheeted cracks' (DO1701). (e) Botryoidal dolomite from the Dengying Formation (ZK430-botr). All thin sections are $2.5 \mathrm{~cm}$ wide (vertical direction). Botryoid targets analysed in this work are shown in red outlines (polarising microscopy) and orange outlines (micro-Raman). 

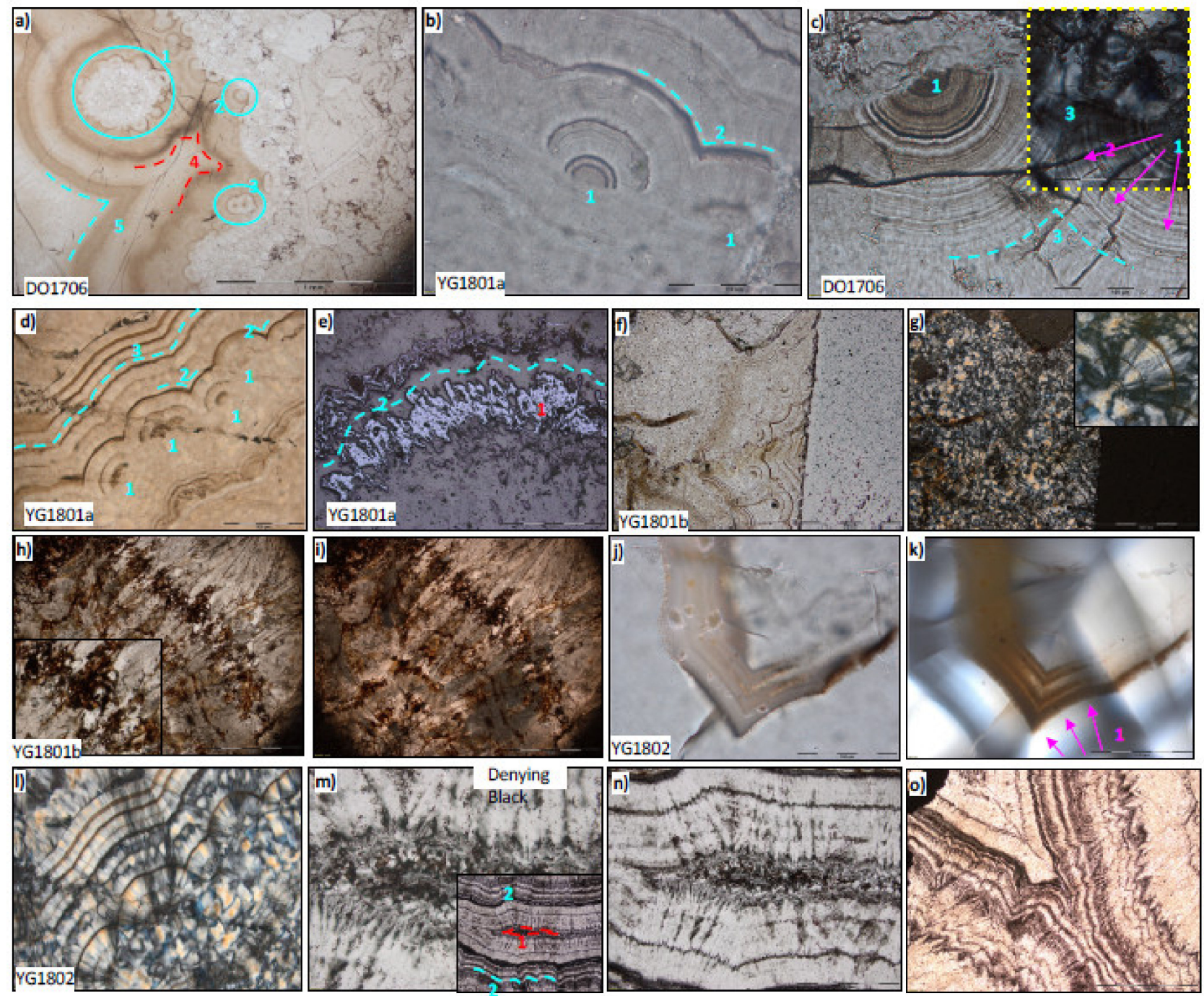

Figure 6. Microscopy images of the studied samples. (a) plane polarised light image of a section of D01706 showing features of spherical botryoids as clusters onto a large central botryoid (1), lone circular botryoids (2), pairs of botryoids growing close together (3), cavity structure (4), and open book structure with intersected circularly concentric laminations (5). (b) plane polarised image of a section of YG1801a showing features of part botryoids (1) and open book banding intersection (2). (c) Plane polarised light image of a section of DO1706 where the inside yellow dotted square is the cross-polarised light image of the same section of rock superimposed onto the main image. There are features of part botryoids (1) in both plane and cross polarised light with the magenta arrows (2) that indicate the radial crystal growth pattern direction. Note that in cross-polarised light there is a clear line of the intersection (3) between the two botryoidal growths where the form an open-book structure. (d) Plane polarised light image of YG1801a showing botryoids (1) associated with curved laminations formed of intersected circularly concentric laminations. (e) Reflected light image of YG1801a that show a sub-circular layer of sub-radially aligned blade of Fe-oxides (1) with equidistant laminations, and (f-g) Botryoids of fine grained quartz with circularly concentric laminations of organic matter and radially aligned acicular quartz, best seen under cross polars in $(\mathrm{g})$ and in its inset, where darkened 'iron cross' domains flare outward and at about 90o from each other, a tell-tale sign of sphericity. (h,i) Plane and cross polarised light images of sub-radially aligned blades of carbonate stained with filamentous black-opaque organic matter (zoom shown in inset for YG1801b), which forms a chaotic band lining the cavity structure. ( $\mathbf{j}, \mathbf{k}$ ) open-book structure in coarse quartz and (1) botryoids in fine quartz from YG1802. (m-o) Plane polarised light images from the Dengying carbonate specimen that show an elongated cavity (1) formed from sub-parallel bands (2) in the fabric of radial, bladed carbonate crystals (note high order interference colours in inset of $\mathrm{m}$ ), which are coated with black organic matter concentrated specifically along grain boundaries and inside the cavity structure ( $\mathbf{m}-\mathbf{n})$. As seen in the quartz specimens from the Doushantuo Fm, laminations are contrasted by the variable concentrations of disseminated organic matter, which yield colour gradients in laminations (seen in o). 
Polarised microscopy images show clusters of small botryoids onto a larger central botryoid, while some botryoids occur as pairs or alone, but they are associated with cavity and open book structures (Figure $6 a-b$ ), where destructive interference produces intersections between circularly concentric laminations. In sheeted cracks some botryoids have several dozen circularly concentric laminations and these are systematically in fine grained quartz (Figure 6c). Most botryoids however have less than ten clear laminations of organic matter with colour gradients. In some cases, sub-circular layers contain subradially aligned blades of iron oxides with equidistant thickness (Figure 6e). These bands of iron oxides blades are similar to, but have less perfect geometry than pure quartz botryoids in fine quartz (Figure 6f,g). Indeed, cross polarised light images show botryoids have banded iron cross features that indicate their spherical morphology (Figure 6g, inset). Carbonate are aligned sub-radially along cavities (Figure 6h,i) and they are stained with filamentous black organic matter, which does not exhibit a typical microbial texture (Figure 6h, inset). Open book structures are common, including in coarse quartz (Figure 6j,k) and botryoids in fine quartz tend to be more geometrically perfect (Figure 61). In the Dengying carbonate, plane polarised light images reveal that elongated cavities are formed by sub-parallel bands of radial, bladed carbonate crystals (Figure $6 \mathrm{~m}, \mathrm{n}$ ), which are coated with black organic matter concentrated specifically along grain boundaries and inside the cavity structure. Lastly, laminations in botryoidal carbonate exhibit contrast due to the variable concentration of disseminated organic matter, which yield colour gradients in these laminations (Figure 6o). Hence botryoidal, nodular, and concretionary quartz have patterns that share many morphological similarities with the self-similar patterns of BZ reactions, including under different reactant conditions and with geologically relevant additives. These patterns are also self-similar since the same kinds of geometric forms repeat over micrometric to decimetric scales.

\subsection{Raman Imaging of Quartz Botryoids from Doushantuo Cap Carbonate}

Raman hyperspectral imaging is widely used in geobiology to investigate the relationships between organic matter and associated minerals. Here, Raman hyperspectral imaging is used to demonstrate beyond any doubt that the composition of the botryoidal bands in quartz consist of organic matter, coloured in red in the four selected hyperspectral images in Figure $7 \mathrm{a}-\mathrm{d}$. Average spectra of organic matter extracted from these datasets show a strong and broad D1 peak either at 1346 or $1385 \mathrm{~cm}^{-1}$, and a resolvable shoulder D4-peak at $1250 \mathrm{~cm}^{-1}$ (Figure 7e). These spectra also show a strong and narrow G-peak at $1608 \mathrm{~cm}^{-1}$, collectively consistent with highly disordered organic matter that has been heated during metamorphism. Estimated peak metamorphic temperatures, are comparable between the Lahfid et al. [27] geothermometer calibrated against organic matter from Cenozoic Helvetic flysch metamorphosed in a low-grade metamorphic gradient, and the Kouketsu et al. [28] geothermometer calibrated against organic matter from Mesozoic Japanese mudstones, as shown in Table 2. 

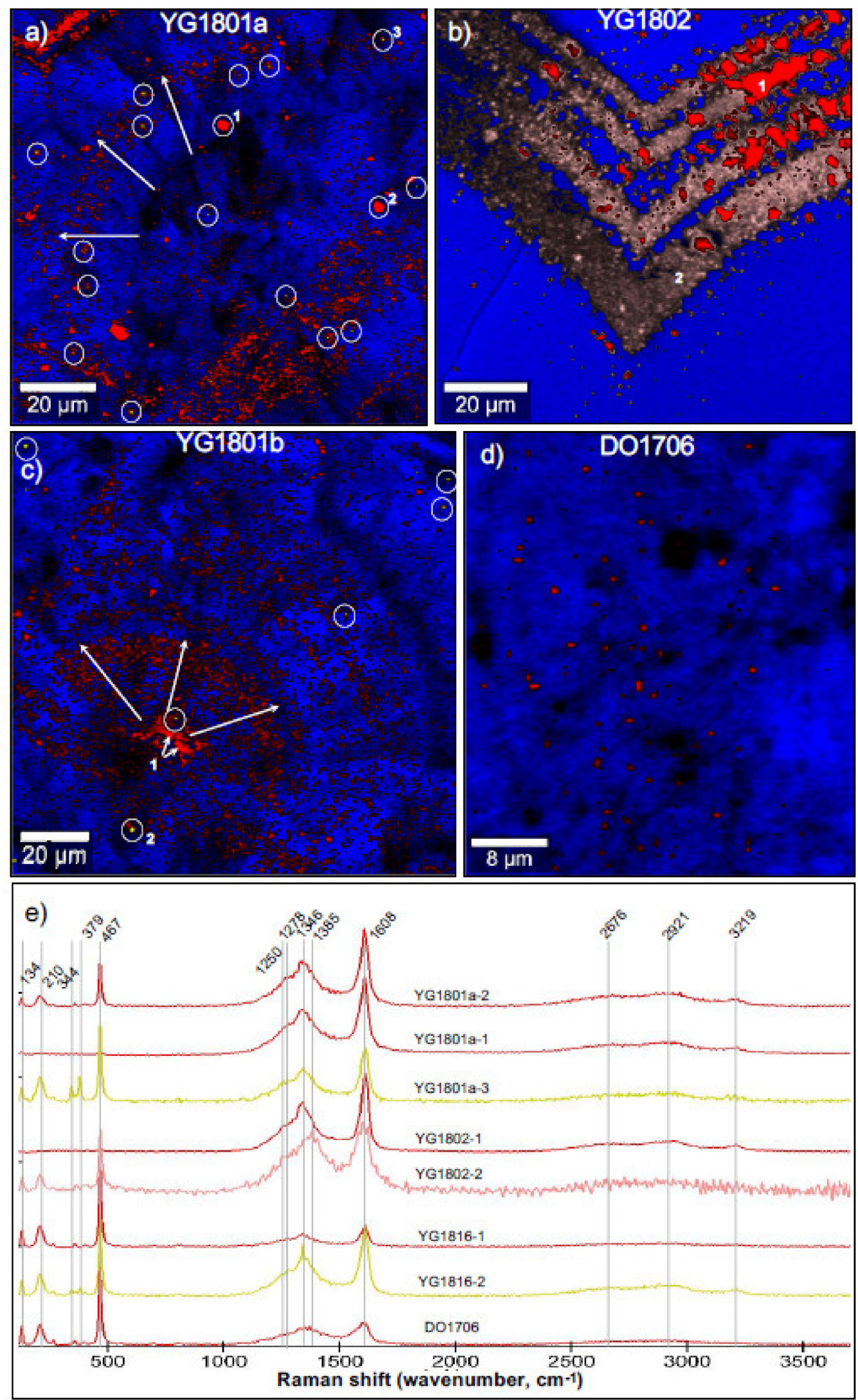

Figure 7. Raman hyperspectral images of organic matter in Doushantuo cap carbonate member 1. (a) Hyperspectral image of organic matter (red) associated with radially aligned acicular quartz (blue) and nanoscopic pyrite (yellow) (YG1801a, Jiulongwan). 
Note the gradients (white arrows) of disseminated organic matter that forms circularly concentric layers akin to the color gradients seen in B-Z experiment. (b) Hyperspectral image of the contact between two sets of circularly concentric laminations composed of two types of organic matter (1 and 2) (YG1802; Jiulongwan). (c) Hyperspectral image of a quartz rosette inside botryoidal quartz with circularly-concentric laminations composed of organic matter and with dense organic matter in its geometric centre. Note the presence of nanoscopic pyrite often associated with organic matter and the gradients of abundance of organic matter aligned radially with acicular quartz (YG1816; Jiulongwan). (d) Hyperspectral image of botryoidal quartz associated with finely disseminated organic matter from 'sheeted cracks' (DO1706; Beidoushan). (e) Raman spectra of variably oxidized organic matter with different D1 peaks or associated with nanoscopic pyrite (yellow spectra).

Table 2. Raman spectral parameters for the main peaks of organic matter in the four spectra analysed (Figure 7e), modelled to calculate peak metamorphic temperatures.

\begin{tabular}{|c|c|c|c|c|c|}
\hline $\begin{array}{c}\text { Spectral } \\
\text { Parameters }\end{array}$ & Sample & $\begin{array}{c}\text { Dengying Carbonate } \\
\text { Botryoid }\end{array}$ & YG1801a & YG1802 & YG18016 \\
\hline \multirow{3}{*}{ G-peak } & Peak position & 1601 & 1585 & 1608 & 1580 \\
\hline & Peak FWHM & 36 & 45 & 32 & 60 \\
\hline & Peak area & 14,800 & 1500 & 28,500 & 435 \\
\hline \multirow{3}{*}{ D1-peak } & Peak position & 1343 & 1347 & 1337 & 1350 \\
\hline & Peak FWHM & 110 & 112 & 100 & 120 \\
\hline & Peak area & 27,500 & 6500 & 57,000 & 2050 \\
\hline \multirow{3}{*}{ D2-peak } & Peak position & 1620 & 1610 & 1620 & 1610 \\
\hline & Peak FWHM & 20 & 25 & 11 & 29 \\
\hline & Peak area & 2500 & 2260 & 2100 & 920 \\
\hline \multirow{3}{*}{ D3-peak } & Peak position & 1510 & 1510 & 1510 & 1510 \\
\hline & Peak FWHM & 150 & 130 & 140 & 130 \\
\hline & Peak area & 8000 & 1200 & 11,000 & 280 \\
\hline \multirow{3}{*}{ D4-peak } & Peak position & 1245 & 1249 & 1245 & 1250 \\
\hline & Peak FWHM & 100 & 109 & 80 & 115 \\
\hline & Peak area & 9000 & 1990 & 10,000 & 764 \\
\hline \multirow{2}{*}{$\begin{array}{l}\text { Correlation } \\
\text { coefficients }\end{array}$} & $\mathrm{R}^{2}$ & 0.9729 & 0.9835 & 0.9852 & 0.9798 \\
\hline & $\mathrm{R}$ & 0.9896 & 0.9917 & 0.9926 & 0.9899 \\
\hline \multirow{3}{*}{$\begin{array}{l}\text { Peak metamorphic } \\
\text { temperature * }\end{array}$} & Model $1\left({ }^{\circ} \mathrm{C}\right)$ & 268.5 & 319.3 & 301.4 & 320.9 \\
\hline & Model $2\left({ }^{\circ} \mathrm{C}\right)$ & 260.6 & 320.4 & 297.9 & 322.5 \\
\hline & Model $3\left({ }^{\circ} \mathrm{C}\right)$ & 241.6 & 237.3 & 263.1 & 220.1 \\
\hline
\end{tabular}

${ }^{*}$ Models 1 and 2 come from Lahfid et al. [27] and they are based on $\mathrm{T}_{1}=(\mathrm{RA} 1-0.3758) / 0.0008$ and $\mathrm{T}_{2}=(\mathrm{RA} 2-0.27) / 0.0045$ and where the RA1 and RA2 values are calculated using peak areas as follows: RA1 $=(\mathrm{D} 1+\mathrm{D} 4) /(\mathrm{D} 1+\mathrm{D} 2+\mathrm{D} 3+\mathrm{D} 4+\mathrm{G})$ and RA2 $=(\mathrm{D} 1+\mathrm{D} 4) /(\mathrm{D} 2+$ D3 + G). Model 3 comes from Kouketsu et al. [28] for comparison, but is considered less reliable since it uses only the FWHM of the D1 for the temperature estimate $(\mathrm{T}=(-2.15 \times(\mathrm{FWHM}-\mathrm{D} 1)+478.1)$.

Calculated peak metamorphic temperatures in Jiulongwan (Doushantuo) and Baizhu (Dengying) are between 260 and $323^{\circ} \mathrm{C}$ using the Lahfid et al. [27], with the slightly higher temperature from Jiulongwan. This is significantly higher than the temperature estimate calculated with the Kouketsu et al. [28], which yields peak metamorphic temperatures between 220 and $263{ }^{\circ} \mathrm{C}$ for the Doushantuo organic matter and $242{ }^{\circ} \mathrm{C}$ for the Dengying. Notably also, the quartz botryoids from Jiulongwan are closely associated with sub-micron size pyrite crystals (white circles in Figure 7a,c). Pyrite is detected by its weak, sharp, and narrow doublet peaks at 344 and $379 \mathrm{~cm}^{-1}$ (Figure 7e). However, these were not found in the sheeted crack quartz botryoid from Beidoushan (Figure 7d). Unfortunately, the signal to noise ratio for the spectra of organic matter for sheeted crack sample DO1706 is too low for reliable calculation of peak temperatures. In summary, in quartz and carbonate botryoids, laminations are produced by gradients of concentration of finely disseminated organic matter, which is indigenous, disordered and metamorphosed, and both reduced and oxidised Fe-phases can occur as iron oxides and pyrite within the circularly concentric patterns. 


\subsection{Molecular Functional Groups in Organic Matter from Niutitang Concretions in Black Shale}

Spectroscopy with synchrotron-generated X-rays is a very useful technique to characterise the molecular functionality of organic matter in geological specimens [29-33]. Ordinary organic matter extracted from the Niutitang black shale near the CambrianPrecambrian boundary show slightly different composition for the decimetric carbonate concretions and the host black shale matrix. X-ray spectra of organic matter in the carbonate concretion shows a major peak (pre-edge) at $285.1 \mathrm{eV}$ (Figure 8a,b) that represents the $1 \mathrm{~s}-\pi^{*}$ electronic transition in aromatic or olefine molecular functional groups and the C-edge at $293.0 \mathrm{eV}$. There is a shoulder peak at $286.8 \mathrm{eV}$ (Figure 8c), which has been previously attributed, respectively, to the $1 \mathrm{~s}-\pi^{*}$ electronic transition in imine $(C=N)$, nitrile $(C \equiv N)$, carbonyl $(\mathrm{C}=\mathrm{O})$ and/or phenolic $(\mathrm{Ar}-\mathrm{OH})$ groups [34-36]. This is followed by a prominent peak at $288.6 \mathrm{eV}$ (Figure $8 \mathrm{c}$ ), which is interpreted as the $1 \mathrm{~s}-\pi^{*}$ electronic transition in carboxylic groups $(\mathrm{COOH})$, ester $(\mathrm{COOR})$ or acetal $\left(\mathrm{C}(\mathrm{OR})_{2}\right)$ groups (at 288.5-288.7 $\mathrm{eV}$ ) [37]. In geological organic matter however, the $288.6 \mathrm{eV}$ peak is most commonly attributed to carboxyl functional groups [32,33,38]. This implies a significant amount of residual carboxylic acids in organic matter inside concretions from the Niutitang Fm. X-ray spectra also confirm the presence of amide, imine and nitrile groups as shown by a peak at $401.5 \mathrm{eV}$, before the N-edge at $404.5 \mathrm{eV}$ (Figure $8 \mathrm{~d}, \mathrm{e}$ ), and carboxyl groups are confirmed by the strong signal from the O-XANES spectrum. In fact, the presence of carboxylic groups is also independently confirmed by a pre-edge peak at $532.1 \mathrm{eV}$ (Figure $8 \mathrm{f}$ ), which has previously been attributed to amide and/or carboxyl carbonyl [39]. The origin of two O-edge, tiny, and resolved peaks at the O-edge at 538.1 and $539.1 \mathrm{eV}$ is unclear, however, a similar peak distribution is observed for OM in the black shale matrix (Figure $8 \mathrm{~g}-\mathrm{l}$ ). The main difference is the relatively smaller level of carboxyl in the OM from the matrix compared to the concretion (Figure $8 \mathrm{c}, \mathrm{i}$ ), which also appears as a lower $\mathrm{O} / \mathrm{C}$ ratio in $\mathrm{OM}$ from the black shale matrix (Figure 8e,l). 
$\underline{\text { YG0902b (carbonate concretion) }}$

a)

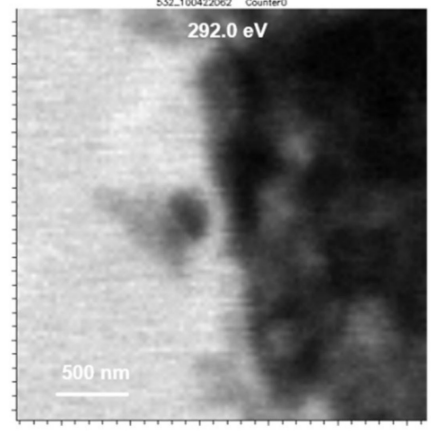

d)

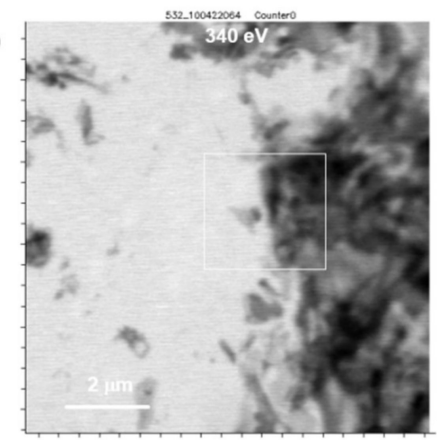

g)

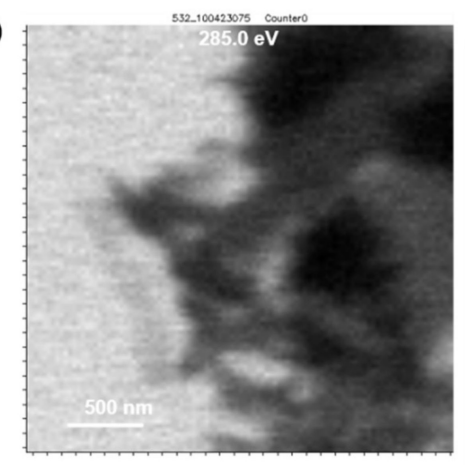

j)

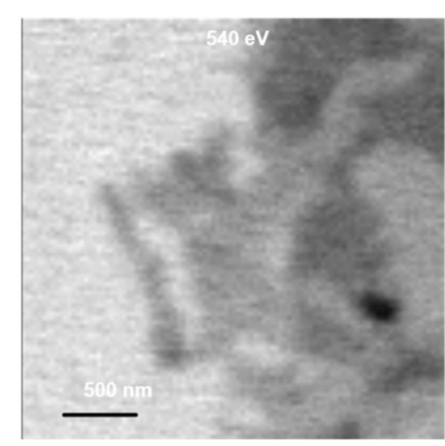

b) 10

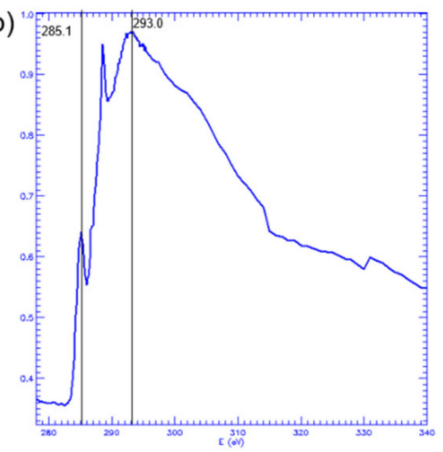

e)

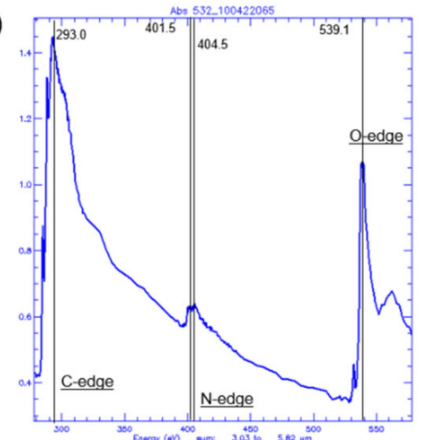

YG0902a (black shale matrix)

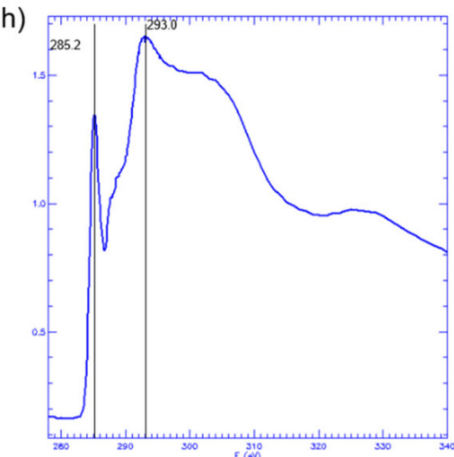

k)

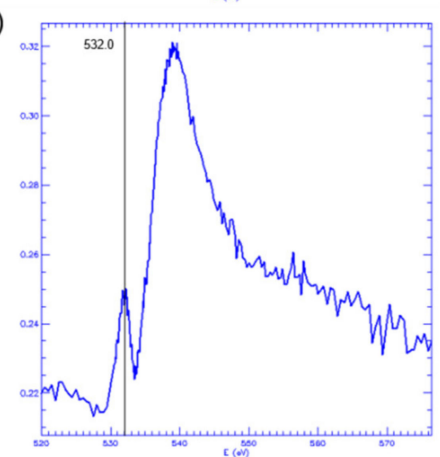

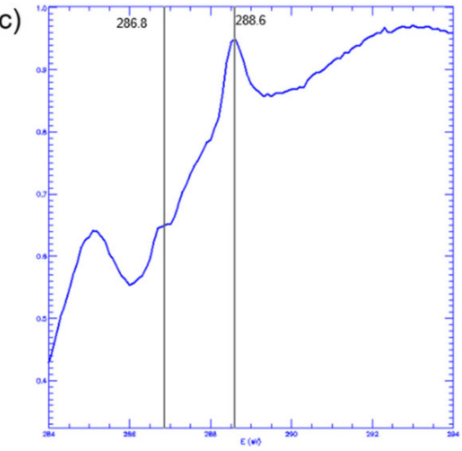

f)

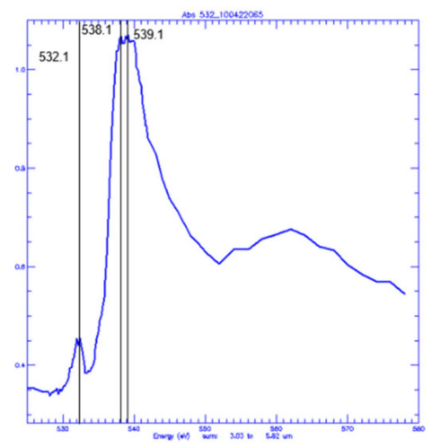

i)

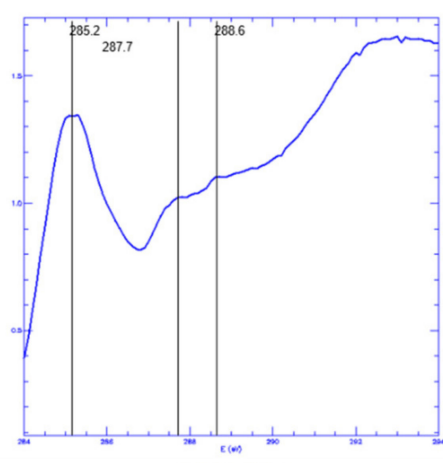

l)

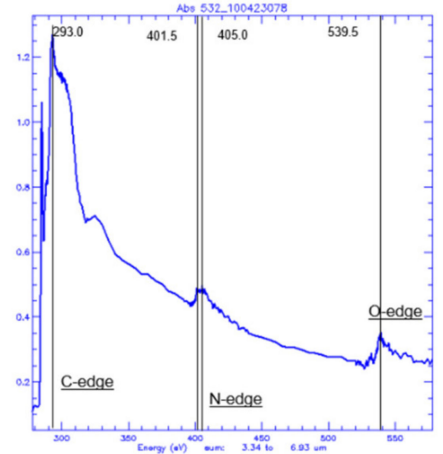

Figure 8. X-ray images and spectra of organic matter extracted from Niutitang black shale. For the carbonate concretion: (a) STXM image at $292.0 \mathrm{eV}$ showing strong absorption of light by the organic matter. (b) C-EXAFS region with the two main edge peaks at 285.3 and $293.0 \mathrm{eV}$, (c) C-XANES spectrum with two resolvable peaks identified at 286.8 and $288.6 \mathrm{eV}$ from molecular groups, (d) image at $340 \mathrm{eV}$ showing a variety of contrast in the organic matter, (e) full X-ray spectrum covering the range of the $\mathrm{C}, \mathrm{N}$, and $\mathrm{O}$ edges, and (f) O-XANES spectrum, which shows three resolvable peaks. For the black shale matrix: (g) STXM image of organic matter at $285.0 \mathrm{eV}$, (h) C-EXAFS region with the same two main peaks as before, (i) C-XANES spectrum that shows a depressed region with two resolvable peaks at 287.7 and $288.6 \mathrm{eV}$, (j) STXM image at $540 \mathrm{eV}$ showing at least three different contrast levels of gray shades, (k) O-XANES spectrums showing a peak at $532.0 \mathrm{eV}$, and (l) full X-ray absorption spectrum over the range of energies for the $\mathrm{C}, \mathrm{N}$, and $\mathrm{O}$ edges. 


\section{Discussion}

5.1. Self-Similar, Fractal Patterns in Chemically Oscillating Reactions and in Botryoidal Quartz and Carbonate

\subsubsection{Comparisons of Geometry, Compositions, Dimension Size}

Here, we objectively compare the morphology and dimensions of the experiments and the types of patterns seen in each experiment (Figure 9). Firstly, the morphology of these self-similar patterns consists of circularly concentric chemical wave with characteristic intersections and gradients of colours. The same general features of circularly concentric patterns, destructively interfered circular wave, cavities, colour gradients, and open book structures also occur in quartz and carbonate botryoids (Table 1). Secondly in the latter, the circularly concentric laminations are composed of organic matter, whereas in the experiment, the exact composition of each chemical wave is a technical challenge that has not yet been experimentally analysed. However, from the reactants used in our experiments we can predict that the chemical waves are composed of variably reduced ferroin, halogens, sulfate, and carboxylic acids. The reactants also imply that sulphur intermediates from sulphate to sulphide should be produced during chemically oscillating reactions, transiently as metastable compounds, which is consistent with the occurrence of micron-size pyrite in quartz botryoid from Jiulongwan. Thirdly, iron oxides and iron sulphides occur within quartz botryoids, which indicates redox reactions involving Fe took place during the diagenetic formation of these structures, analogously to the phenanthroline ferrous sulphate used in experimental chemically oscillating reactions. It is also strikingly similar that organic matter in botryoids forms many patterns: (1) circularly concentric laminations themselves defined by finely disseminated organic matter; (2) gradients of concentration; (3) contours of cavity structures; (4) open book structures; (5) sub-parallel banding through destructively interfered successive circular laminations; (6) linearly elongated cavities; (7) half rosettes and (8) low to high wave periods (Figure 9). In addition to these morphological and compositional similarities, we note that the self-similar BZ patterns in chemically oscillating reactions span at least three orders of magnitude in size dimension (from 103 to $10-1 \mathrm{~m}$ ), which is comparable but larger than self-similar patterns in quartz and carbonate botryoids (from 10-5 to 10-1 m). Hence, these kinds of patterns can be considered fractal patterns and identical between chemically oscillating reactions and quartz and carbonate botryoids. 


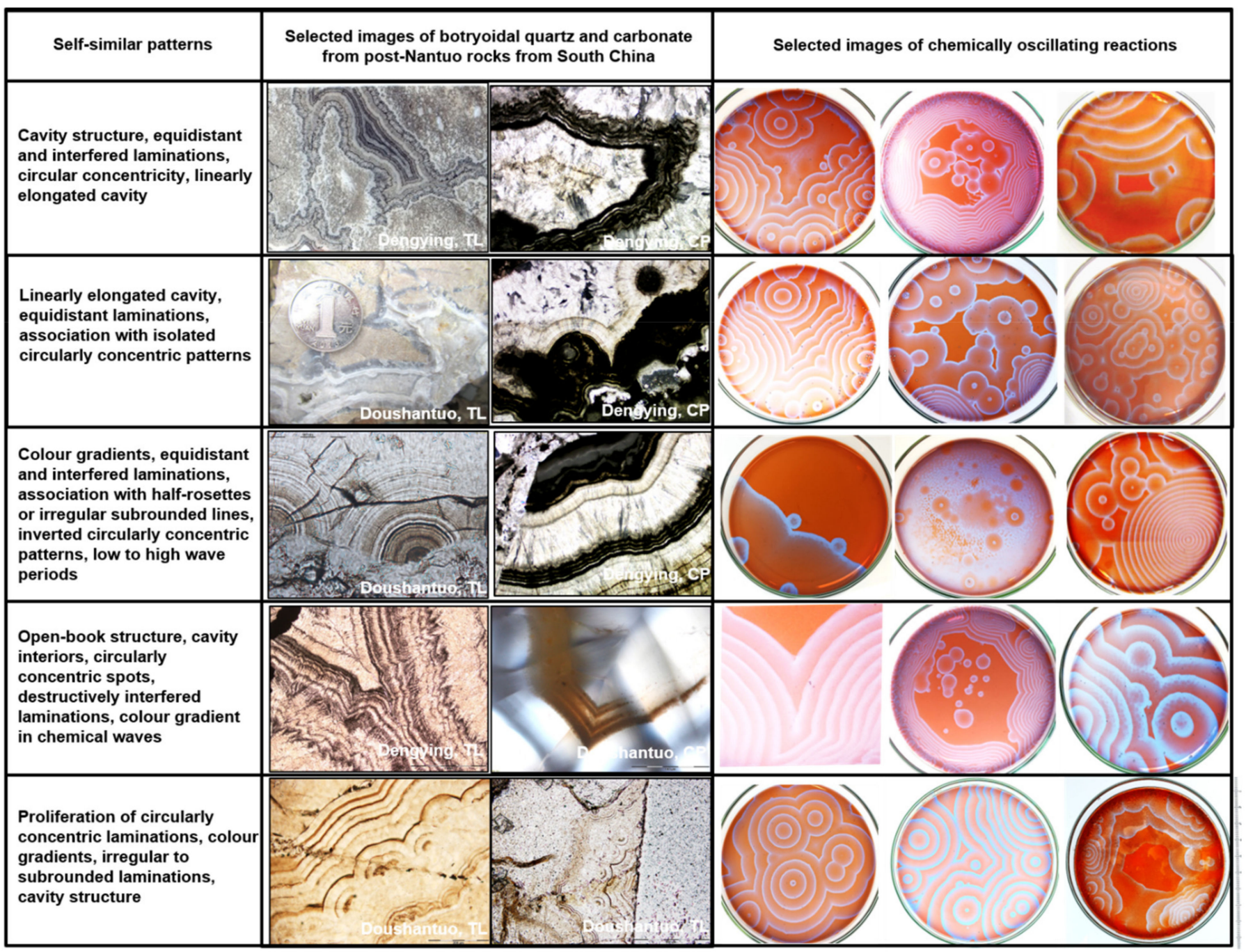

Figure 9. Summative and comparative grid of patterns (Table 1) shared by botryoidal quartz and carbonate, with images from the post-Nantuo of South China, directly compared with selected B-Z experiments, which also produced these patterns. TL is transmitted light (i.e., plane polarized) and CP is cross polarised (i.e., crossed nicols).

\subsubsection{An Imperfect Comparison}

However, the match is not perfect either: fingerprint-like patterns such as those observed in some chemically oscillating reactions do not clearly occur in sedimentary rocks. Perhaps such patterns occur as the enigmatic 'Eozoon' pseudofossils, which has a similar zebra-like pattern, however these do not occur in the Doushantuo nor Dengying formations to our knowledge, and thus not all the patterns observed in chemically oscillating reactions are also observed in rocks. Spiral patterns are also not clearly observed in sedimentary rocks. Besides spiral-shaped fossils, spiral patterns may be represented by a crystallographic type of pattern. In fact, crystallographic analyses have demonstrated that individual acicular and radially aligned crystals of quartz in agate geodes have a crystal structure that consists in a spiral-like, screw dislocation space group [2]. While this was not verified in this work, quartz botryoids from Jiulongwan are shown to be composed of similar radially aligned acicular quartz crystals (Figure 6g,l), which show the same kinds of geometric features and self-similar fractal patterns as those in agate geodes. Hence, the spiral patterns of chemically oscillating reactions in mineral botryoids may be hidden in the crystal structures' space group as screw dislocations. Another dissimilarity is the fact the experiments are performed essentially in two-dimensions, in a thin film of aqueous solution covering the 
bottom of the Petri dish, whereas all botryoids in nature occur as three-dimensional objects. On the last point however, it can be considered that Petri dish experiments with thin aqueous films could represent cross-sections of this phenomena in three-dimensions, which is best argued based on the variable lengths of colour gradients in chemical waves.

\subsubsection{Effects of Colloidal Silica vs. Humic Acid}

While features described from the patterns seen in chemically oscillating reaction experiments are mostly two dimensional and confined to a Petri dish, however the same fractal nature of these patterns allows the features to be compared directly. Experiments without humic acid or colloidal silica additives consistently produced more oxidation spots, richer patterns and often nearly perfect circularly concentric laminations. The timescale of the classical BZ reaction would typically be around forty-five min after the first occurrence of an oxidation spot until it becomes filled with compact lines and becomes dominated by spirals. In the experiments with solid humic acid additives, the spirals usually begin to form closer to the start of the reaction alongside oxidation spots. However, humic acid particles do not appear to directly participate in the reaction since the chemical wave are neither triggered or influenced by the presence of humic acid. However, new experiments with colloidal silica show that it participates directly in chemically oscillating reactions as seen with masses of colloidal silica that disrupt and cross-cut chemical waves (Figure 4b Right and Figure 4c Right). Small amounts of colloidal silica added to a BZ solution produces an environment in thermodynamic non-equilibrium (e.g., with very different $\mathrm{pH}$ ), which is expected during the putrefaction of biomass [40]. These conditions can produce decimetre size, circularly concentric patterns that are geometrically centered on the clump of silica (Figure 4c Left). Large clumps of colloidal silica cause an acceleration of the formation of spiral patterns, which more quickly dominate the patterns (Figure 4c, right). Furthermore, in these experiments with abundant clumps of colloidal silica (Figure 4e,f), the frequency of chemical waves produced is higher and colloidal silica clearly perturbs or facilitates pattern formation, including the preservation of ferric- and ferrous-rich areas (Figure 4f). Lastly, uniformly distributed colloidal silica also leads to the production of self-similar fractal patterns with circularly concentric laminations, cavity structures, and open book structures (Figure 4d). However, colloidal silica appears to slow down the propagation of chemical waves, while the rate of chemical wave production in the experimental chemically oscillating reaction remains constant, which results in a smaller distance between bands, or higher frequency of chemical waves. These observations thus validate the hypothesis that self-similar fractal patterns are produced and directly influenced by alkaline colloidal silica. This also supports a possible role for colloidal silica to contribute to the self-catalysis of chemically oscillating reactions, which is supported by the increased abundance of $\mathrm{CO}_{2}$ bubbles in the dishes with more silica additives.

\subsubsection{Comparison with Mineralised Organic Decomposition during Early Diagenesis in Nature}

Chemically oscillating reaction are expected during early organic diagenesis, as the decarboxylation of carboxylic acid is a natural phenomenon during the decomposition of biomass. The main inorganic ingredients, such as sulphate, halogens and Fe, are also expected to become concentrated during diagenesis and sulphate and halogens are also known to become transiently more abundant during global oxygenation events (e.g., Neoproterozoic Oxidation Event and Great Oxidation Event-[41-43]; Hardisty et al., 2014). This sets the stage to argue that these abiotic reactions can take place during the natural diagenetic maturation of biomass, especially after early deamination and transamination reactions during protein decomposition [44]. These early reactions, along with organo-silica complexes (Escario et al., 2020), produce significant alkalinity and increase $\mathrm{pH}$ to above 8 in pore water solutions, towards silica solubility. This is followed by decarboxylation reactions and a concomitantly lower $\mathrm{pH}$ that comes with carbonic acid release from intermediary metabolites, amino acids, and phospholipids [45]. Hence, alkaline conditions during early diagenesis are expected to precipitate colloidal silica, which becomes metastable and 
insoluble in aqueous solutions as $\mathrm{pH}$ decreases. Subsequent decarboxylation of biomass during putrefaction contributes much $\mathrm{CO}_{2}$ and characteristically odorful carboxylic acid volatiles, which lowers the $\mathrm{pH}$. The gel-like aqueous solution with colloidal silica then starts to precipitate apatite (if enough $\mathrm{P}$ is present), pyrite (if enough $\mathrm{Fe}^{2+}$ and $\mathrm{S}^{-}$are present) and carbonate when the $\mathrm{pH}$ reaches about 10.5 and keeps decreasing to about 8. It is thus inevitable that the original reactants in the pre-botryoid aqueous solutions in diagenetic pore waters included carboxylic acids from biomass, inorganic oxidants, and iron (and trace metals and rare Earth elements) catalysts. Instead, the patterns in quartz botryoids from Doushantuo cap carbonate mimic those created by the experimental chemically oscillating reactions and they are thus most parsimoniously explained by such specific, spontaneous, abiotic, non-equilibrium, redox, and pattern-forming reactions.

\subsubsection{Organic Geochemistry of Autochthonous Botryoidal Quartz}

As botryoidal structures are usually dismissed as secondary mineralization, it is important to recognize here that the organic matter in these rocks is indigenous and autochthonous, that is, as old as the host rock, and any remobilization occurred within the rock prior to or during metamorphism. The microscopy observations that organic matter is intimately associated with the laminations in the quartz botryoids, and the fact that carboxylic acids are essential reactants to produce fractal patterns, represent an undeniable connection between the chemically oscillating reactions and botryoidal quartz. Importantly also, the petrological relationships between $\mathrm{OM}$ and quartz in the botryoids do not suggest that oil migration took place, as it is in place where it can be expected from chemically oscillating reactions. Also, oil migration and the process of mineral replacement cannot explain the near-perfect geometry of these self-similar fractal patterns nor the fine disseminations of organic matter and pyrite in botryoidal quartz. Instead, observations show quartz and carbonate botryoids contain organic matter typically defining the botryoid laminations, but there is also notable sub-micron size pyrite and iron oxides consistent with abiotic sulphate reduction and ferrous iron oxidation during chemical oscillations, as predictable from the reactants used in experiments. In fact, Raman images (Figure 7a-d) show botryoids of quartz lined with circularly concentric laminations of organic matter with the same characteristic self-similar fractal patterns as the main features produced by chemically oscillating reactions, including in experiments with malonic, succinic, and $\alpha$-ketoglutaric acids and colloidal silica.

The organic matter within botryoids also have Raman spectra data (Figure 6e) characteristic of metamorphically heated disordered organic matter with variable levels of molecular functional groups, seen in part with variably resolved D4-peaks for instance. With the Kouketsu et al. [28] model, we calculated peak metamorphic temperatures of $220{ }^{\circ} \mathrm{C}$ to $263{ }^{\circ} \mathrm{C}$ for the Doushantuo and around $242{ }^{\circ} \mathrm{C}$ for the Dengying Formation. Higher ranges of peak metamorphic temperatures are calculated using the Lahfid et al. [27] geothermometer, which are in excess of $320^{\circ} \mathrm{C}$ in the Three Gorges area and about $270{ }^{\circ} \mathrm{C}$ for the Dengying Fm near Baizhu. Since the estimates based only on the full width at half maximum (FWHM) of a single peak (D1) from Kouketsu et al. [28], which also has significant overlaps with the D3 and D4 peaks and possibly also D5 near $1455 \mathrm{~cm}^{-1}$ [46], and which all represent different molecular functional groups, we consider these temperature estimates to be less reliable and minimal estimates that those calculated with the Lahfid et al. [27] thermometer. However, these temperature estimates are similar to those determined on organic matter from phosphorite in Doushantuo Member II between $220{ }^{\circ} \mathrm{C}$ and $350{ }^{\circ} \mathrm{C}$ in the Three Gorges area [47] and between $290{ }^{\circ} \mathrm{C}$ and $360{ }^{\circ} \mathrm{C}$ in the Baizhu and Weng'an [48]. Hence, we consider that organic in quartz and carbonate botryoids from Member I in Jiulongwan and Beidoushan have been metamorphosed at temperatures less than $320^{\circ} \mathrm{C}$. A major implication from these observations is that the organic matter is autochthonous and was present during botryoid formation and therefore suggests that pattern production was from the oxidation of biomass in the presence of colloidal silica, which would be responsible for the formation of radially-aligned, acicular 
quartz growing as diagenetic spheroids. Not only this is the simplest explanation, but it is also the only explanation consistent with the three main criteria explored in this work: the morphology of the self-similar patterns, the composition of reactants and products, and the range of dimensions of sizes expressed by the patterns.

\subsection{Implications for the Post-Snowball Earth Conditions}

Carboxylic acids are common in nature and contain carbon, oxygen, and hydrogen, which are expected to occur in organic matter from the Doushantuo and Dengying Formations. New X-ray spectra point to the significant presence of carboxylic molecular functional groups in organic matter from carbonate concretions in the early Cambrian Niutitang Fm., although carboxylic groups are also preserved in lesser relative amounts in organic matter from the host black shale (Figure 8c,i). While only these two sub-samples were analysed, the observation of high levels of carboxylic groups in organic matter from a concretion contemporaneous with the Doushantuo and Dengying Formations, points to the widespread presence of carboxylic acid in the diagenetic environments of the studied botryoidal concretionary structures. The inferred presence of nitrile molecular functional groups if also notable, although none of these peaks are surprising as they have been variably reported in organic matter from various rocks, for instance in lower Toarcian oil shales from Germany [32], in late Paleoproterozoic stromatolitic phosphorite from Rajasthan [4], and in microfossiliferous chert from the Paleoarchean and Paleoproterozoic $[5,37,49]$. Hence, we conclude that carboxylic acids were omnipresent also in the Doushantuo and Dengying depositional environments and therefore, common ones in microorganisms like malonic, succinic, and $\alpha$-ketoglutaric acids were available to fuel chemically oscillating reactions during diagenesis.

Hence, the presence of quartz botryoidal crusts lining the inside of concretionary cavities in the Ediacaran cap carbonate of the Doushantuo Fm, a classical locality for studies on the Snowball Earth and Neoproterozoic Oxygenation Event, may be secondary after deposition, but the underlying processes of chemically oscillating reactions took place during early organic diagenesis. This can be understood simply as mineralised decomposition, since the mineralogy dominated by quartz requires a soluble precursor like a colloidal silica gel and organic matter requires a precursor abundant. On a $\mathrm{pH}$ path, this alkalinity during organic decomposition would eventually be lowered by the production of carbonic acid and lead to the sequential precipitation of colloidal silica, collophane apatite (if enough phosphoric acid is present in pore waters, and finally carbonate micrite from decarboxylation reactions. The formation of cavities lined with botryoidal quartz in Member I and in the Dengying carbonate is thus expected to have taken place simultaneously with the embedding matrix, which is composed of dolomitic to calcitic carbonate with generally negative to highly negative $\delta^{13} C_{\text {carb }}$ values $[13,18,20]$. As the latter geochemical signatures could be explained by decarboxylation of biomass, more studies are needed to establish the exact correlation of ${ }^{13} \mathrm{C}$-depleted carbonate with botryoids and other diagenetic spheroids. There are thus many connections that now need to be explored between chemically oscillating reactions, other botryoidal mineral occurrences, climate change after a snowball Earth event (and possibly with smaller climatic fluctuations), fossilization with botryoids, and the carbon cycle.

Chemically oscillating reactions are shown in this work to be preserved in unusual cap carbonate, and therefore the ${ }^{13} \mathrm{C}$-depletions may have an origin at least related to sedimentary processes involved in organic diagenesis, but the sources of reactants in the Doushantuo diagenetic environment need to be explored further. Organic matter is found in all types of quartz and carbonate botryoids studied and it generally occurs as disseminations, forms curvilinear gradients of concentrations that define the circular concentricity of botryoids. It is associated with microscopic iron oxides and nanoscopic pyrite in botryoids, and also concretions [50] and in granules [47], in which microscopic pyrite forms equidistant rims, occurs as fossil replacements, and terminates ambient inclusion trails (AIT) such as in granular phosphorites from Member II [48] These objects are usually argued to have 
formed as a product of abiotic sulphate reduction during diagenesis. Higher seawater sulphate and iodate concentrations have also been inferred in Member I and throughout the Doushantuo Fm. For instance, seawater sulphate concentrations have been inferred to have been higher during the deposition of the Doushantuo Fm and most studies have shown large range of $\delta^{34} S_{\text {pyrite }}$ and $\delta^{34} S_{\text {CAS }}$ values (CAS is carbonate associated sulphate), but these tend to go from positive to negative (from about $+40 \%$ to $-20 \%$ in pyrite) from Member I to IV [18,20,51], in the intra-shelf locality at Jiulongwan. This indicates that sulphate was in abundance in the post-Snowball Doushantuo seawater and since sulphate is usually supplied from oxidatively weathered crustal sulphides, the concomitant acidity created is also supplied and part of diagenetic pore waters. In addition, the chemically oscillating reactions in the Doushantuo Fm are interpreted to have also required some iodate or bromate, which has been inferred to be higher during the deposition of the Doushantuo $\mathrm{Fm}$, and specifically, there are $\mathrm{I} /(\mathrm{Ca}+\mathrm{Mg})$ concentration excursions that coincide with both EN1 and EN3 [52,53]. Lastly, the last reactant of chemically oscillating reactions to consider for the Doushantuo environment are carboxylic acids. These commonly biological molecules were also abundant in post-glacial seawater, as this can be inferred directly from the abundance of organic matter and microfossils previously documented in detail in Member II and interpreted to represent cyanobacterial blooms [19,47]. With high levels of biomass, such oxygenated and oxidant-rich pore waters solutions were ideal sites for chemically oscillating reactions and the formation of concretionary botryoidal structures.

\subsection{Broad Significance of Botryoid Mineral Formation: From Mineralogy to Exobiology}

Botryoidal quartz is found in ancient sedimentary rocks that date from at least the Paleoarchean, for instance in the Dresser Fm where it has been associated with methanogenesis performed by Archaea [12]. The presence of quartz botryoidal crusts lining the inside of cavities in the Ediacaran cap carbonate of the Doushantuo Fm, a classical locality for studies on the Neoproterozoic Oxygenation Event, snowball Earth, and some of the earliest animal and algal fossils. These are clearly secondary to deposition, but the underlying processes took place during early diagenesis, after deposition, and before initial lithification and metamorphism. Raman spectra show small differences in the structure of organic matter in quartz botryoids in the position of the D1-peak between 1346 and $1385 \mathrm{~cm}^{-1}$, and the intensity of the D4-peak between 1250 and $1274 \mathrm{~cm}^{-1}$. This suggests the variable presence and abundance of molecular functional groups, but since the general spectral characteristics are nearly identical, we do not favour a foreign or later origin or influence from migrated hydrocarbons. Molecular functional groups such as carboxyl and nitrile occur in organic matter from Cambrian concretions, and since these are commonly observed, they are inferred to have been present in Ediacaran biomass, and probably since the origin of life on Earth. The differences in relative abundance may also be an effect of chemically oscillating reactions. However, they are expected to deplete the reactants of carboxyl, so there may be other functional groups in organic matter from Niutitang concretions. Nevertheless, it can be concluded that carboxylic acids are ubiquitous where there is life on Earth, such that their abiotic decomposition in the presence of strong acids and oxidisers can be expected to lead to botryoidal mineralisation. It may then be suggested that botryoidal minerals might be indicative of a previously unrecognised connection with the carbon cycle and decarboxylation reactions [42].

The formation of botryoidal quartz and carbonate involves a process related to the decarboxylation of carboxylic acids and thus a part of the biogeochemical carbon cycle. In fossils from the geological record, botryoids occur and can display a variety of colours. These colourful displays of chemical oscillations thus relate mineralogy and sedimentology with fossilization, carbon cycling, and climate change. Lastly, since botryoids may thus be possible biosignatures, the discovery reported here is relevant to prebiotic chemistry [54], chemical gardens [55], mineral evolution [56], and the search for extra-terrestrial life [57]. It is indeed suggested that chemically oscillating reactions could be important for prebiotic chemistry as an analogue of the early evolution of biochemical metabolisms and the 
early evolution of abiotic electron transport chains, including those akin to the inferred electrochemical origin of organic matter in Martian meteorites [58]. We also note the many similarities between the tricarboxylic acid cycle and the classical BZ reaction, including the origin of metal cofactors in the TCA and reverse TCA cycles [54], which might be related to the various trace metals that can colour botryoidal quartz. These phenomena also share similarities with ferroin, which is phenanthroline ferrous sulphate, where the redoxsensitive Fe ion is coordinated by the $\mathrm{N}$ atoms of three phenanthroline macromolecules (two pyridine rings bridged by a benzene ring). Biochemical similarities also exist between the self-catalytic, redox-sensitive Fe atom, which simultaneously coordinated by three phenanthroline molecules in chemically oscillating reactions, and the coordination of metals in cyctochromes used to transport electrons and harvest energy inside cellular membranes. New chemical garden experiments using these kinds of compounds [52] might be informed by the new results presented here, as some of the rosettes associated with botryoids have been considered dubiofossils of uncertain origin. Some concretions are associated with frutexites, another kind of dubiofossil, such as in rounded zeolite concretions from the bottom of the Mariana Trench [59]. In terms of evolutionary changes, concretions and botryoids have not been systematically studied and therefore a new area is opening in the field of mineral evolution, which describes the timeline of circumstances of the emergence the various $>5300$ minerals known [56,60]. Lastly, if quartz and carbonate botryoids and concretions represent a possible biosignature or at least an abiotic signature of carbon cycling, then these objects should become top priority for detailed further analysis when possibly observed on another planetary surface (e.g., [61]). In fact, abiotic chemically oscillating reactions in nature, for instance on a lifeless planetary surface with fluid circulation, could be involved in a prebiotic-type of abiotic carbon cycle through serial redox reactions similar to electron transfer in metabolic biochemistry. Botryoidal minerals may thus be relevant to many fields of Earth and planetary sciences, and since they may be a sedimentological signature of the carbon cycle, they are also relevant to exobiology and the search for biosignatures of ancient extra-terrestrial life. In this work, new details on the substance, morphology, and patterns are presented as biosignatures [57]. The self-catalysis of decarboxylation reactions during chemically oscillating reactions produces self-similar patterns in experiments as well as in botryoidal quartz and carbonate.

\section{Summary and Conclusions}

There is close similarity between the self-similar fractal patterns produced by chemically oscillating reactions and those exhibited by quartz and carbonate botryoids. In both cases, electrons are provided from carboxylic acids, and they are transferred through several intermediary molecules that end with strong oxidants. New experiments show that chemically oscillating reactions (with a $\mathrm{pH}$ around 2) also occur and produce patterns in highly alkaline solutions in the presence of colloidal silica ( $\mathrm{pH}$ around 12), but the latter has a direct involvement in pattern formation, which can be disrupted or triggered by the presence of colloidal silica. In comparison, particles of humic acid do not interact with the self-similar patterns. The self-similar patterns can be described as circularly concentric waves, each with its own gradient, and where they intersect, yield an erased to partly erased trace, ultimately leading to cavities, isolated rosettes, and open book structures, as well as producing visible $\mathrm{CO}_{2}$ bubbles.

Botryoids of quartz in cap carbonates and in carbonate rocks constitute sedimentological evidence for the diagenetic oxidation of biological carboxylic acids after the Nantuo glaciation. Mineralogical evidence in Doushantuo and Dengying botryoids shows circularly concentric waves with gradients of organic matter concentrations, layered disseminations of nanoscopic pyrite in that organic matter, and occasional layers of iron oxides. Authochtonous organic matter indicates peak metamorphic temperatures in excess of $320^{\circ} \mathrm{C}$ in the Doushantuo Member I in the Three Gorges area and about $270{ }^{\circ} \mathrm{C}$ for the Dengying Fm near Baizhu. Acid-insoluble organic matter from concretions in black shale from the slightly younger Niutitang Fm contain nitrile and carboxylic functional 
groups, and also possibly imine, nitrile, amide, carbonyl, phenolic, ester, and/or acetal molecular functional groups. These compositions are collectively consistent with a role for carboxylic acid, which in this case originated from cyanobacterial blooms, involved in abiotic reactions with a redox-sensitive Fe and the original presence of sulphate, for chemically oscillating reactions to spontaneously contribute to the mineralisation of botryoidal quartz and carbonate.

It is also likely that botryoids share a similar origin as other chemical precipitates in the form of other diagenetic quartz and carbonate spheroids, including geodes, framboids, ooids, pisoids, rosettes, granules, botryoids, and concretions. There should be a broader search for minerals associated with organic matter in mineralised spheroidal to concentric structures with a possible sedimentary-diagenetic origin. The presence of cavities with quartz botryoids specifically in post-snowball Earth glacial sediments with ${ }^{13} \mathrm{C}$-depleted carbonate is consistent with diagenetic-sedimentary processes being at least partly responsible for this unusual geochemical signal. However, these processes likely started during post-glacial high-productivity in the water column, including accretionary growth of microbial colonies [19,47], which has been suggested to have redox gradients on the basis of co-varying $\delta^{13} \mathrm{C}$ values in organic matter and carbonate. Hence, chemically oscillating reactions are relevant to mineralogy, sedimentary diagenesis, the carbon biogeochemical cycle, (micro-)palaeontology, paleoclimatology, and by extension to prebiotic chemistry, evolutionary biochemistry, and the search for biosignatures of extra-terrestrial life. While chemically oscillating reactions have been largely ignored in geological sciences so far, there is a great outlook for their consideration and integration in future studies, and it is predicted here that they will help to solve important problems in Earth and planetary sciences.

Author Contributions: Conceptualization, D.P.; Formal analysis, D.P. and J.Y.; Funding acquisition, D.L. and Z.S.; Investigation, D.P. and J.Y.; Methodology, D.P.; Field work, Z.S., D.L. and D.P.; Project administration, D.P.; Supervision, D.P.; Writing—original draft, D.P. and J.Y.; Writing-review \& editing, K.G.D., D.L. and Z.S. All authors have read and agreed to the published version of the manuscript.

Funding: Field work was funded by the National Natural Science Foundation of China (grants 41772362 to D.L. and 41272038 to Z.S.) and by the State Key Laboratory of BioGeology and Environmental Geology, China University of Geosciences (grant GBL11801).

Data Availability Statement: All relevant data is shown and described in the manuscript and no additional is made available at the moment.

Acknowledgments: D.P. acknowledges fruitful discussions on this topic with J. Götze, G. Shields, N. Lane, and E. Oelkers as well as continuing support from the LCN, UCL, and CUG-Wuhan. M. Crosby is acknowledged and thanked for preparing solutions for the BZ reaction and J. Davy is acknowledged for his skillful preparation of polished thin sections. Field work in Three Gorges and Baizhu was supported by National Natural Science Foundation of China (grant \# 41272038).

Conflicts of Interest: The authors declare no conflict of interest.

\section{References}

1. Götze, J.; Zenz, J. Agate-fascination between legend and science. In Agates III; Bode Verlag: Salzhemmendorf, Germany, 2011; pp. 19-133.

2. Heaney, P.J.; Davis, A.M. Observation and origin of self-organized textures in agates. Science 1995, 269, 1562-1565. [CrossRef] [PubMed]

3. Götze, J.; Möckel, R.; Pan, Y. Mineralogy, geochemistry and genesis of agate-A review. Minerals 2020, 10, 1037. [CrossRef]

4. Papineau, D.; De Gregorio, B.; Fearn, S.; Kilcoyne, D.; McMahon, G.; Purohit, R.; Fogel, M. Nanoscale petrographic and geochemical insights on the origin of the Palaeoproterozoic stromatolitic phosphorites from Aravalli Supergroup, India. Geobiology 2016, 14, 3-32. [CrossRef] [PubMed]

5. Papineau, D.; She, Z.; Dodd, M.S. Chemically-oscillating reactions during the diagenetic oxidation of organic matter and in the formation of gran- ules in late Palaeoproterozoic chert from Lake Superior. Chem. Geol. 2017, 470, 33-54. [CrossRef]

6. Dodd, M.S.; Papineau, D.; She, Z.; Fogel, M.L.; Nederbragt, S.; Pirajno, F. Organic remains in late Palaeoproterozoic granular iron formations and im-plications for the origin of granules. Precambrian Res. 2018, 310, 133-152. [CrossRef] 
7. Papineau, D. Chemically oscillating reactions in the formation of botryoidal malachite. Am. Mineral. 2020, 105, 447-454. [CrossRef]

8. Gabriel, N.W.; Papineau, D.; She, Z.; Leider, A.; Fogel, M.L. Organic diagenesis in stromatolitic dolomite and chert from the late Palaeoproterozoic McLeary Formation. Precambrian Res. 2021, 354, 106052. [CrossRef]

9. Zaikin, A.; Zhabotinsky, A. Concentration wave propagation in two- dimensional liquid-phase self-oscillating system. Nature 1970, 225, 535-537. [CrossRef] [PubMed]

10. Hofmann, H. Global distribution of the Proterozoic sphaeromorph acritarch Valeria lophostriata (Jankauskas). Wei ti gu Sheng wu xue bao. Acta Micropalaeontol. Sin. 1999, 16, 215-224.

11. Som, S.M.; Buick, R.; Hagadorn, J.W.; Blake, T.S.; Perreault, J.M.; Harnmeijer, J.P.; Catling, D. Earth's air pressure 2.7 billion years ago constrained to less than half of modern levels. Nat. Geosci. 2016, 9, 448-451. [CrossRef]

12. Ueno, Y.; Yamada, K.; Yoshida, N.; Maruyama, S.; Isozaki, Y. Evidence from fluid inclusions for microbial methanogenesis in the early Archaean era. Nature 2006, 440, 516-519. [CrossRef]

13. Jiang, G.; Kennedy, M.; Christie-Blick, N. Stable isotopic evidence for methane seeps in Neoproterozoic postglacial cap carbonates. Nat. Cell Biol. 2003, 426, 822-826. [CrossRef]

14. Condon, D.; Zhu, M.; Bowring, S.; Wang, W.; Yang, A.; Jin, Y. U-Pb Ages from the Neoproterozoic Doushantuo Formation. China Sci. 2005, 308, 95-98. [CrossRef]

15. Chen, Y.-Q.; Jiang, S.-Y.; Ling, H.-F.; Yang, J.-H. Pb-Pb dating of black shales from the Lower Cambrian and Neoproterozoic strata, South China. Geochemistry 2009, 69, 183-189. [CrossRef]

16. Barfod, G.H.; Albarède, F.; Knoll, A.H.; Xiao, S.; Télouk, P.; Frei, R.; Baker, J. New Lu-Hf and Pb-Pb age constraints on the earliest animal fossils. Earth Planet. Sci. Lett. 2002, 201, 203-212. [CrossRef]

17. Zhou, C.; Li, X.-H.; Xiao, S.; Lan, Z.; Ouyang, Q.; Guan, C.; Chen, Z. A new SIMS zircon U-Pb date from the Ediacaran Doushantuo Formation: Age constraint on the Weng'an biota. Geol. Mag. 2017, 154, 1193-1201. [CrossRef]

18. McFadden, K.A.; Xiao, S.; Zhou, C.; Kowalewski, M. Quantitative evaluation of the biostratigraphic distribution of acanthomorphic acritarchs in the Ediacaran Doushantuo Formation in the Yangtze Gorges area, South China. Precambrian Res. 2009, 173, 170-190. [CrossRef]

19. She, Z.-B.; Strother, P.; Papineau, D. Terminal Proterozoic cyanobacterial blooms and phosphogenesis documented by the Doushantuo granular phosphorites II: Microbial diversity and C isotopes. Precambrian Res. 2014, 251, 62-79. [CrossRef]

20. Li, C.; Love, G.D.; Lyons, T.W.; Fike, D.A.; Sessions, A.L.; Chu, X. A Stratified Redox Model for the Ediacaran Ocean. Science 2010, 328, 80-83. [CrossRef] [PubMed]

21. Zhu, M.; Lu, M.; Zhang, J.; Zhao, F.; Li, G.; Aihua, Y.; Zhao, X.; Zhao, M. Carbon isotope chemostratigraphy and sedimentary facies evolution of the Ediacaran Doushantuo Formation in western Hubei, South China. Precambrian Res. 2013, 225, 7-28. [CrossRef]

22. Cui, H.; Xiao, S.; Cai, Y.; Peek, S.; Plummer, R.E.; Kaufman, A.J. Sedimentology and chemostratigraphy of the terminal Ediacaran Dengying Formation at the Gaojiashan section, South China. Geol. Mag. 2019, 156, 1924-1948. [CrossRef] [PubMed]

23. Zhu, G.; Wang, P.; Li, T.; Zhao, K.; Yan, H.; Li, J.; Zhou, L. Nitrogen geo- chemistry and abnormal mercury enrichment of shales from the lowermost Cambrian Niutitang Formation in South China: Implications for the marine redox conditions and hydrothermal activity. Glob. Planet. Chang. 2021, 199, 103449. [CrossRef]

24. Alexander, C.M.O.; Fogel, M.; Yabuta, H.; Cody, G.D. The origin and evolution of chondrites recorded in the elemental and isotopic compositions of their macromolecular organic matter. Geochim. Cosmochim. Acta 2007, 71, 4380-4403. [CrossRef]

25. Kilcoyne, A.; Tyliszczak, T.; Steele, W.F.; Fakra, S.; Hitchcock, P.; Franck, K.; Anderson, E.; Harteneck, B.; Rightor, E.G.; Mitchell, G.E.; et al. Interferometer-controlled scanning transmission X-ray microscopes at the Advanced Light Source. J. Synchrotron Radiat. 2003, 10, 125-136. [CrossRef]

26. Papineau, D.; De Gregorio, B.T.; Sagar, J.; Thorogate, R.; Wang, J.; Nittler, L.; Kilcoyne, D.A.; Marbach, H.; Drost, M.; Thornton, G. Fossil biomass preserved as graphitic carbon in a late Paleoproterozoic banded iron for-mation metamorphosed at more than $550{ }^{\circ}$ C. J. Geol. Soc. 2019, 176, 651-668. [CrossRef]

27. Lahfid, A.; Beyssac, O.; Deville, E.; Negro, F.; Chopin, C.; Goffé, B. Evolution of the Raman spectrum of carbonaceous material in low-grade metasediments of the Glarus Alps (Switzerland). Terra Nova 2010, 22, 354-360. [CrossRef]

28. Kouketsu, Y.; Mizukami, T.; Mori, H.; Endo, S.; Aoya, M.; Hara, H.; Nakamura, D.; Wallis, S. A new approach to develop the Raman carbonaceous material geothermometer for low-grade metamorphism using peak width. Isl. Arc. 2014, 23, 33-50. [CrossRef]

29. Bernard, S.; Benzerara, K.; Beyssac, O.; Menguy, N.; Guyot, F.; Brown, G.E., Jr.; Goffé, B. Exceptional preservation of fossil plant spores in high-pressure metamorphic rocks. Earth Planet. Sci. Lett. 2007, 262, 257-272. [CrossRef]

30. Bernard, S.; Benzerara, K.; Beyssac, O.; Brown, G., Jr.; Stamm, L.G.; Duringer, P. Ultrastructural and chemical study of modern and fossil sporoderms by Scanning Transmission X-ray Microscopy (STXM). Rev. Palaeobot. Palynol. 2009, 156, 248-261. [CrossRef]

31. Bernard, S.; Beyssac, O.; Benzerara, K.; Findling, N.; Tzvetkov, G.; Brown, G., Jr. XANES, Raman and XRD study of anthracenebased cokes and saccharose-based chars submitted to high-temperature pyrolysis. Carbon 2010, 48, 2506-2516. [CrossRef]

32. Bernard, S.; Horsfield, B.; Schulz, H.-M.; Wirth, R.; Schreiber, A.; Sherwood, N. Geochemical evolution of organic-rich shales with increasing maturity: A STXM and TEM study of the Posidonia Shale (Lower Toarcian, northern Germany). Mar. Pet. Geol. 2012, 31, 70-89. [CrossRef] 
33. Boyce, C.K.; Cody, G.D.; Feser, M.; Jacobsen, C.; Knoll, A.H.; Wirick, S. Organic chemical differentiation within fossil plant cell walls detected with X-ray spectromicroscopy. Geology 2002, 30, 1039-1042. [CrossRef]

34. Myneni, S.C.B. Soft X-ray Spectroscopy and Spectromicroscopy Studies of Organic Molecules in the Environment. Rev. Mineral. Geochem. 2002, 49, 485-579. [CrossRef]

35. Shard, A.G.; Whittle, J.D.; Beck, A.J.; Brookes, P.N.; Bullett, N.A.; Talib, R.A.; Mistry, A.; Barton, D.; McArthur, S.L. A NEXAFS examination of un- saturation in plasma polymers of allylamine and propylamine. J. Phys. Chem. B 2004, 108, 12472-12480. [CrossRef]

36. Nuevo, M.; Milam, S.; Sandford, S.; De Gregorio, B.; Cody, G.; Kilcoyne, A. XANES analysis of organic residues produced from the UV irradiation of astrophysical ice analogs. Adv. Space Res. 2011, 48, 1126-1135. [CrossRef]

37. Alleon, J.; Bernard, S.; Le Guillou, C.; Marin-Carbonne, J.; Pont, S.; Beyssac, O.; McKeegan, K.D.; Robert, F. Molecular preservation of $1.88 \mathrm{Ga}$ Gunflint organic microfossils as a function of temperature and mineralogy. Nat. Commun. 2016, 7, 11977. [CrossRef]

38. Cody, G.; Botto, R.; Ade, H.; Wirick, S. The application of soft X-ray microscopy to the in-situ analysis of sporinite in coal. Int. J. Coal Geol. 1996, 32, 69-86. [CrossRef]

39. Cody, G.D.; Gupta, N.S.; Briggs, D.E.; Kilcoyne, A.; Summons, R.E.; Kenig, F.; Plotnick, R.E.; Scott, A. Molecular signature of chitin-protein complex in Paleozoic arthropods. Geology 2011, 39, 255-258. [CrossRef]

40. Berner, R.A. Calcium carbonate concretions formed by the decomposition of organic matter. Science 1968, 159, 195-197. [CrossRef]

41. Li, C.; Hardisty, D.S.; Luo, G.; Huang, J.; Algeo, T.J.; Cheng, M.; Shi, W.; An, Z.; Tong, J.; Xie, S.; et al. Uncovering the spatial heterogeneity of Ediacaran carbon cycling. Geobiology 2017, 15, 211-224. [CrossRef]

42. Papineau, D.; Mojzsis, S.J.; Schmitt, A.K. Multiple sulfur isotopes from Paleoproterozoic Huronian interglacial sediments and the rise of atmospheric oxygen. Earth Planet. Sci. Lett. 2007, 255, 188-212. [CrossRef]

43. Hardisty, D.S.; Lu, Z.; Planavsky, N.J.; Bekker, A.; Philippot, P.; Zhou, X.; Lyons, T.W. An iodine record of Paleoproterozoic surface ocean oxygenation. Geology 2014, 42, 619-622. [CrossRef]

44. Boyd, S.R. Nitrogen in future biosphere studies. Chem. Geol. 2001, 176, 1-30. [CrossRef]

45. Sheik, C.S.; Cleaves, H.J.; Johnson-Finn, K.N.; Giovannelli, D.; Kieft, T.L.; Papineau, D.; Schrenk, M.O.; Tumiati, S. Abiotic and biotic processes that drive carboxylation and decarboxylation reactions. Am. Mineral. 2020, 105, 609-615. [CrossRef]

46. Ferralis, N.; Matys, E.D.; Knoll, A.H.; Hallmann, C.; Summons, R.E. Rapid, direct and non-destructive assessment of fossil organic matter via microRaman spectroscopy. Carbon 2016, 108, 440-449. [CrossRef]

47. She, Z.-B.; Strother, P.; McMahon, G.; Nittler, L.R.; Wang, J.; Zhang, J.; Sang, L.; Ma, C.; Papineau, D. Terminal Proterozoic cyanobacterial blooms and phosphogenesis documented by the Doushantuo granular phosphorites I: In situ micro-analysis of textures and composition. Precambrian Res. 2013, 235, 20-35. [CrossRef]

48. She, Z.-B.; Zhang, Y.-T.; Liu, W.; Song, J.; Zhang, Y.; Li, C.; Strother, P.; Papineau, D. New observations of Ambient Inclusion Trails (AITs) and pyrite framboids in the Ediacaran Doushantuo Formation, South China. Palaeogeogr. Palaeoclimatol. Palaeoecol. 2016, 461, 374-388. [CrossRef]

49. Alleon, J.; Bernard, S.; Le Guillou, C.; Beyssac, O.; Sugitani, K.; Robert, F. Chemical nature of the 3.4 Ga Strelley Pool microfossils. Geochem. Perspect. Lett. 2018, 37-42. [CrossRef]

50. Xiao, S.; Schiffbauer, J.D.; McFadden, K.A.; Hunter, J. Petrographic and SIMS pyrite sulfur isotope analyses of Ediacaran chert nodules: Implications for microbial processes in pyrite rim formation, silicification, and exceptional fossil preservation. Earth Planet. Sci. Lett. 2010, 297, 481-495. [CrossRef]

51. Cui, H.; Kaufman, A.J.; Xiao, S.; Zhou, C.; Liu, X.-M. Was the Ediacaran Shuram Excursion a globally synchronized early diagenetic event? Insights from methane-derived authigenic carbonates in the uppermost Doushantuo Formation, South China. Chem. Geol. 2017, 450, 59-80. [CrossRef]

52. Hardisty, D.S.; Lu, Z.; Bekker, A.; Diamond, C.W.; Gill, B.; Jiang, G.; Kah, L.C.; Knoll, A.H.; Loyd, S.J.; Osburn, M.R.; et al. Perspectives on Proterozoic surface ocean redox from iodine contents in ancient and recent carbonate. Earth Planet. Sci. Lett. 2017, 463, 159-170. [CrossRef]

53. Wei, H.; Wang, X.; Shi, X.; Jiang, G.; Tang, D.; Wang, L.; An, Z. Iodine content of the carbonates from the Doushantuo Formation and shallow ocean redox change on the Ediacaran Yangtze Platform, South China. Precambrian Res. 2019, 322, 160-169. [CrossRef]

54. Muchowska, K.B.; Varma, S.J.; Chevallot-Beroux, E.; Lethuillier-Karl, L.; Li, G.; Moran, J. Metals promote sequences of the reverse Krebs cycle. Nat. Ecol. Evol. 2017, 1, 1716-1721. [CrossRef]

55. Barge, L.M.; Cardoso, S.S.S.; Cartwright, J.H.E.; Cooper, G.J.T.; Cronin, L.; De Wit, A.; Doloboff, I.J.; Escribano, B.; Goldstein, R.; Haudin, F.; et al. From Chemical Gardens to Chemobrionics. Chem. Rev. 2015, 115, 8652-8703. [CrossRef]

56. Hazen, R.M.; Papineau, D.; Bleeker, W.; Downs, R.T.; Ferry, J.M.; McCoy, T.J.; Sverjensky, D.A.; Yang, H. Mineral evolution. Am. Minerol. 2008, 93, 1693-1720. [CrossRef]

57. Chan, M.A.; Hinman, N.W.; Potter-McIntyre, S.L.; Schubert, K.E.; Gillams, R.J.; Awramik, S.M.; Boston, P.J.; Bower, D.M.; Des Marais, D.J.; Farmer, J.D.; et al. De-ciphering biosignatures in planetary contexts. Astrobiology 2019, 19, 1075-1102. [CrossRef] [PubMed]

58. Steele, A.; Benning, L.G.; Wirth, R.; Siljeström, S.; Fries, M.D.; Hauri, E.; Conrad, P.G.; Rogers, K.; Eigenbrode, J.; Schreiber, A.; et al. Organic synthesis on Mars by electrochemical reduction of CO. Sci. Adv. 2018, 4, eaat5118. [CrossRef] [PubMed] 
59. Peng, X.; Guo, Z.; Du, M.; Czaja, A.; Papineau, D.; Chen, S.; Xu, H.; Li, J.; Ta, K.; Bai, S.; et al. Past endolithic life in metamorphic ocean crust. Geochem. Perspect. Lett. 2020, 14, 14-19. [CrossRef]

60. Hazen, R.M.; Bekker, A.; Bish, D.L.; Bleeker, W.; Downs, R.T.; Farquhar, J.; Ferry, J.M.; Grew, E.S.; Knoll, A.H.; Papineau, D.; et al. Needs and opportunities in mineral evolution research. Am. Minerol. 2011, 96, 953-963. [CrossRef]

61. Squyres, S.W.; Arvidson, R.E.; Ruff, S.; Gellert, R.; Morris, R.V.; Ming, D.W.; Crumpler, L.; Farmer, J.D.; Marais, D.J.D.; Yen, A.; et al. Detection of Silica-Rich Deposits on Mars. Science 2008, 320, 1063-1067. [CrossRef] 